\title{
BREVE ESTUDIO Y TRADUCCIÓN CRÍTICA ESPAÑOLA DE DIE KUNST DAS CLAVIER ZU SPIELEN DE FRIEDRICH WILHELM MARPURG (BERLÍN, HENNING, 1750) ${ }^{1}$
}

\author{
BRIEF STUDY AND SPANISH CRITICAL TRANSLATION \\ OF DIE KUNST DAS CLAVIER ZU SPIELEN BY \\ FRIEDRICH WILHELM MARPURG (BERLIN, HENNING, 1750)
}

María de las Nieves Pascual León

Conservatorio Superior de Música de Valencia

\begin{abstract}
Resumen
El presente trabajo supone la primera versión en lengua castellana del tratado de F. W. Marpurg Die Kunst das Clavier zu spielen, que había estado restringido para el lector común de habla hispana desde su primera aparición en 1750. Acompaño esta traducción filológica del tratado (en la que se ofrece al lector la versión facsímil de la primera edición del original en páginas enfrentadas frente a la traducción española), de un breve estudio sobre las diversas ediciones de la obra que vieron la luz en vida del autor, se prentende ofrecer una primera aproximación al tratado, facilitando el acceso del gran público a la obra y contribuyendo a su máxima divulgación.
\end{abstract}

\section{Palabras clave}

Friedrich Wilhelm Marpurg, François Couperin, teclado, ornamentación, digitación, clavecín, Jacob Wilhelm Lustig.

\begin{abstract}
This paper includes the first Spanish version of F. W. Marpurg's treaty Die Kunst das Clavier zu spielen, which had been restricted for the common Spanish-speaking reader since its first appearance in 1750. This philological translation of the treaty (with the facsimile of the first edition and its Spanish translation on the opposite page) is instroduced by a brief study of the text's various editions published during the author's life, and pretends to offer an initial approach to the treaty, to facilitate the public's access to the work and to contribute to its full disclosure.
\end{abstract}

\section{Key words}

Friedrich Wilhelm Marpurg, François Couperin, keyboard, embellishment, fingering, harpsichord, Jacob Wilhelm Lustig.

1 El presente artículo se enmarca en los resultados del proyecto de I+D+I (Programa Estatal de Investigación, Desarrollo e Innovación Orientada a los Retos de la Sociedad) titulado Lo que no se escribe en la música que se escribe: el peso de la tradición oral en la actividad musical profesional y las fuentes en el ámbito hispánico (HAR 2013-48181-C2-1-R). 
A pesar de la importancia de Friedrich Wilhelm Marpurg como compositor $\mathrm{y}$, sobre todo, como teórico, a fecha de hoy apenas se conoce el recorrido biográfico de su figura. El objeto de este artículo es el de contextualizar la publicación de su primer tratado para tecla, El arte de tocar el teclado ${ }^{2}$, estudio que aquí completo con la que supone la primera traducción del tratado en lengua española ${ }^{3}$. Si bien no corresponde a este trabajo profundizar en la biografía de su autor ${ }^{4}$, sí conviene, al menos, mencionar ciertos aspectos de ella que pudieron influir en la redacción del tratado, acercando su comprensión a quien se enfrente a la obra desde la perspectiva interpretativa o musicológica.

El Diccionario de los escritores alemanes actuales de Georg Christoph Hamberger ${ }^{5}$ cita Seehausen como la ciudad natal de F. Marpurg, pero no aporta fecha de nacimiento. Tampoco lo hace el Almanaque Musical de Johann Nikolaus Forkel:

"geb. auf einem Gute in der Altmark, das damals Marpurgshof hieß aber nach der Zeit seinen Namen verändert hat" ${ }^{\prime \prime}$.

Algunos años más tarde, Joahnn Georg Meusel recoge algunos datos más exactos en su Enciclopedia de los compositores alemanes fallecidos entre 1750 y 18007: F. Marpurg habría nacido en 1718 el señorío de Seehausen, en el Altmark, región histórica situada al norte de lo que hoy se conoce como el estado de Sajonia-Anhalt, situado entre las ciudades de Brandeburgo y Magdeburgo. Karl-Heinrich Jördens también recoge esta fecha de nacimiento, y añade que F. Marpurg vivió hasta 1749 en Berlín, donde se dedicó al estudio de la armonía ${ }^{8}$. Sin embargo, esto no parece correcto, como se verá a continuación.

Resulta, cuanto menos, curioso, que incluso a principios de siglo XX todavía no hubiera certeza en relación a los datos biográficos de F. W. Marpurg. Así, la Enciclopedia

2 MARPURG, 1750b.

3 He realizado este estudio y traducción filológica a partir del ejemplar conservado en la Biblioteca Estatal de Baviera, en Múnich (Bayerische Staatsbibliothek München) bajo la signatura 4.Mus.th. 949, con licencia de uso libre. 207-214.

4 Para un estudio biográfico detallado, véase: KUARES, 2003:

5 HAMBERGER y MEUSEL, 1772: 441.

6 "Nacido en un señorío en el Altmark que entonces se llamaba Marpurgshof, pero que con el tiempo ha cambiado de nombre". FORKEL, 1782: 71-72.

7 MEUSEL, 1808: 495.

8 JÖRDENS, 1809: 36.
Universal de Eduard Bernsdorf ${ }^{9}$ da como fecha de nacimiento el 1 de octubre de 1718 , lo cual no coincide con la fecha actualmente aceptada: 21 de noviembre de este mismo año. Del mismo modo, en 1902, Robert Eitner se asombraba de que no existieran testimonios biográficos sobre F. W. Marpurg, si bien afirmaba que disfrutó de una completa formación escolar y universitaria ${ }^{10}$.

En realidad no hay mucha información sobre los años de formación de F. W. Marpurg, aunque quizás la ausencia de datos relativos a maestros o escuelas esté relacionada con un aprendizaje autodidacta y carente de vínculos pedagógicos con los grandes personajes de su tiempo. No obstante, se sabe que estudió Derecho en Jena partir de mayo de 1738, trasladándose en julio de 1739 a Halle, importante ciudad en la época como centro de formación y de práctica musical. No obstante, parece que un enfrentamiento con el compositor y organista Johann Gotthilf Ziegler $(* 1688 ; \uparrow 1747)$ le obligó a abandonar Halle y a trasladarse a París ${ }^{11}$, donde debió de entrar en contacto y, en cierto modo, asimilar el estilo musical francés.

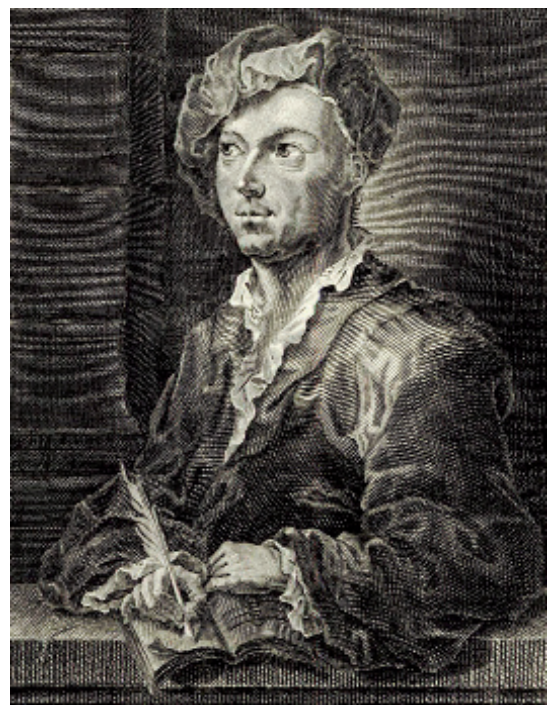

Friedrich Kauke: Calcografía de F. W. Marpurg (1758).

En su Nuevo diccionario histórico-biográfico de compositores, Ernst Ludwig Gerber ${ }^{12}$ hace una calurosa alabanza de F. Marpurg como primer profesor de la ciencia de la música y narra cómo en noviembre de 1793, durante una estancia

9 BERNSDORF, 1857: 887-888.

10 EITNER, 1902: 339.

11 KUARES, 2003: 209-213.

12 GERBER, 1813: 329. 
en Berlín, había tenido ocasión de visitar a F. Marpurg casi a diario. Según el testimonio de E. L. Gerber, a su vuelta de Francia, F. Marpurg habría trabajado durante un tiempo como secretario de un ministro berlinés. Más tarde habría viajado a Hamburgo y finalmente se habría reestablecido en Berlín, ocupando el puesto de director de loterías.

Es en esta época en la que F. W. Marpurg comienza su importante labor como compositor y, sobre todo, como crítico y teórico musical. La importancia de Die Kunst das Clavier zu spielen radica, precisamente, en el hecho de que supone la primera aportación de su autor al campo de la pedagogía musical.

En 1750, F. Marpurg publica El arte de tocar el teclado a través de la imprenta de Henning en Berlín. RISM recoge siete ejemplares de la primera edición, a razón de uno en Bélgica, tres en Alemania, uno en Dinamarca y dos en Estados Unidos ${ }^{13}$. Entre estos ejemplares, por su accesibilidad y calidad de sus imágenes, he utilizado para este trabajo el conservado en la Bayerische Staatsbibliothek de Múnich. De él he extraído los ejemplos musicales y las tablas ilustrativas de la traducción que completa este estudio.

Esta primera edición del tratado cuenta con una extensión de 27 páginas y viene acompañado por cuatro láminas de ejemplos musicales (Tablas I-IV). El título original completo es el de Die Kunst das Clavier zu spielen, durch den Verfasser des Critischen Musicus an der Spree, es decir El arte de tocar el teclado, por el autor de "El músico crítico junto al Esprea".

F. Marpurg había publicado como editor este último título poco tiempo atrás. Se trata de una recopilación los cincuenta fascículos de la publicación periódica homónima, aparecidos periódicamente entre marzo de 1749 y enero de 1750. El mismo autor afirma en el prólogo:

"Es hat verschiedne meiner Leser befremdet, daß dieses Werck mit dem funfzigsten Stücke aufgehöret hat. Sie haben eine Fortsetzung gewünschet, und mich theils mündlich, theils schriftlich dazu ermuntert"14.

De esta alusión se puede pensar que este volumen tuvo una amplia difusión que ayudara a extender la fama de F. Marpurg. Nótese cómo el hecho de que aparezca una referencia a Marpurg en la Violinschule (1756) de L. Mozart indica lo rápido que se estaba difundiendo su obra y hasta qué punto se consideraba a F. W. Marpurg como teórico de referencia a mediados de siglo.

13 LESURE, 1971: 544.

14 MARPURG, 1750a: VII.
Así, cuando F. W. Marpurg publicó ese mismo año $E l$ arte de tocar el teclado, sustituyó su verdadero nombre por la expresión "el autor de "El músico crítico junto al Esprea", en lo que puede considerarse una estretegia de márqueting para atraer al lector que, habiendo conocido el citado título, se interesara ahora por esta nueva publicación del autor.

Aparentemente, esta primera edición debió de contar con pocos ejempares y agotarse en poco tiempo, pues un año más tarde, la imprenta de Haude y Spener, la misma a la que F. Marpurg había confiado la publicación del Critischer Musicus, publicó la segunda edición del tratado, que en realidad se trata de una reimpresión de la primera, sobre la que no incorpora ningún cambio ${ }^{15}$. Además, de este modo, habiendo transcurrido tan poco tiempo después de la primera edición a cargo de Henning, la imprenta de Haude y Spenner buscara atraer al lector con una publicación aparentemente novedosa.

No obstante, cuando en 1760 esta misma imprenta se hizo cargo de la siguiente edición, sí la califica como tal en el título, especificando que se trataba de una tercera edición corregida y ampliada ${ }^{16}$ a cincuenta páginas a partir de las 27 originales. El autor divide el nuevo tratado en una sección introductoria y tres capítulos, dedicados al significado de algunos elementos musicales, a la ornamentación y a la digitación. Además, F. Marpurg suprime la dedicatoria inicial y redacta un nuevo prólogo, en el que afirma:

"Der gute Abgang dieses Werkchens, welches, seiner zahlreichen Abdrücke ungeachtet, innerhalb zehn Jahren nicht allein zweymahl gänzlich vergriffen, sondern annoch, wiewohl auf eine unerlaubte Art, und sehr fehlerhaft, in einer gewissen Reichstadt nachgedruckt worden, zeiget, daß die Existenz desselben dem Publico nicht gleichgültig seyn müsse. Ich bin bey dieser Gütigkeit so wenig unempfindlich, daß ich mich vielmehr auf alle Weise bemühet habe, mich derselben bey dieser dritten rechtmäßigen Ausgabe, die ich nur für die meinige erkennen werde, durch allerhand Zusätze und Veränderungen, annoch würdiger zu machen. Da dieses Werkchen, wie es der Aungenschein giebt, nur bloß den Anfängern des Claviers gewidmet ist: so kann man, wenn man die darinnen abgehandelten Grundsätze dieses Instruments in seiner Gewalt hat, alsdenn meine grössere Anleitung zum Clavierspielen nach der schönern Ausübung der heutigen Zeit etc., zur Hand nehmen"17.

15 MARPURG, 1751.

16 MARPURG, 1760.

17 "La buena trayectoria de esta obrita, que, a pesar de sus numerosas copias, a lo largo de diez años no sólo se ha agotado dos veces por completo, sino que también se ha impreso en cierta ciudad imperial, 
Resulta curiosa la referencia a una edición no autorizada del tratado en una época en la que todavía no existía ninguna base legal que protegiera los derechos de autor. Así, éste se veía realmente perjudicado por esta primitiva forma de "piratería". Su único recurso era, como aquí hace F. Marpurg, el de advertir que sólo determinada edición estaba autorizada y era correcta, o bien hacer modificaciones en el texto o completándolo respecto a la edición original, esperando de este modo que el público deseara adquirir la versión auténtica y actualizada. Por otra parte, llama la atención la escrupulosidad de F. Marpurg frente a ediciones no autorizadas del texto, al mismo tiempo que, como él mismo reconoce, para la redacción de su tratado se inspira en el tratado homónimo y bastante anterior de F. Couperin ${ }^{18}$.

El título al que alude F. Marpurg en la cita anterior corresponde al tratado publicado en 1755 como Introducción a la interpretación de teclado según la buena práctica de la presente época ${ }^{19}$. En este sentido, resulta curiosa la reseña que hace Jacob Adlung en 1758 sobre este último texto, del que afirma supone una edición ampliada de El arte de tocar el teclado, acompañada de 18 tablillas de cobre. Contrariamente a este argumento, el tratado de 1755 no puede considerarse una "segunda edición" del de 1750. Mientras que el texto de 1750 es, esencialmente, un opúsculo de temática esencialmente práctica, centrado en cuestiones de digitación, el tratado de 1755 supone una completa sistematización de contenidos teórico-prácticos y, partiendo de la base teórica más elemental, reúne todos los conocimientos necesarios con el fin de dotar al principiante de las herramientas necesarias para introducirse en la práctica del teclado.

No obstante, el prólogo de la Introducción a la interpretación de teclado sí que resulta revelador a la hora de entender cuál había sido la recepción del tratado de 1750 :

"Die gütige Nachsicht, womit das Publicum meine Kunst das Clavier zu spielen, aufgenommen, hat mich ermuntert, demselben in gegenwärtiger Schrift etwas vollständigers über diese Materie zu liefern. Es giebt Liebhaber, die alles, was zu einer gewissen Sache

si bien de forma no autorizada y con muchos errores, muestra que su existencia no ha debido de resultar indiferente al público. Ante esta generosidad me siento tan poco insensible que, por todos los medios, con todo tipo de añadidos y cambios, me he esforzado en hacer todavía más digna esta tercera edición autorizada, a la que únicamente reconoceré como mía. Como esta obrita, como se percibe a la vista, sólo está pensada para los principiantes del teclado, cuando ya se hayan dominado los fundamentos de este instrumento que se tratan en ella, se podrá acudir a mi más extensa Introducción a la interpretación de teclado según la buena práctica de la presente época, etc.". MARPURG, 1760: II.

18 COUPERIN, 1716.

19 MARPURG, 1755. gehöret, in einem Buche beysammen haben wollen. Noch mehrere giebt es, die des Vortheils einer guten mündlichen Unterweisung nicht allenthalben, oder nicht lange gnug genießen können. Beyden wird vermittelst dieser Anleitung genung geschehen" 20.

De este modo, volviendo al texto que nos ocupa en el presente estudio, se puede pensar que, motivado por la acogida de la primera edición en 1750, el autor se viera obligado a publicar una reimpresión en 1751, que de nuevo gozaría de una considerable difusión, dando pie a ediciones no autorizadas. En este contexto debió de surgir la tercera edición de 1760, en la que F. Marpurg quiso introducir cambios y ampliaciones para distanciarse de las versiones apócrifas. A la hora de actualizar el tratado, F. Marpurg tiene en cuenta su Introducción a la interpretación de teclado, de la que toma gran parte de los contenidos, si bien de forma mucho más comprimida y concisa. Así, esta tercera edición de 1760 , corregida y aumentada como especifica en la portada, presenta un índice de contenidos y está dividida en una introducción y tres capítulos. La introducción y el tercer capítulo, dedicados a consejos previos y a la digitación, sí que entroncan directamente con la primera edición. No obstante, sus contenidos no son idénticos a los expuestos una década atrás. La introducción de esta tercera edición parte del texto de 1750 , sobre el que realiza algunos comentarios sobre la posición y el toque. Por lo que se refiere a la digitación, F. Marpurg invierte el orden en su explicación, dedicándose primero a las escalas y después a los acordes. El formato con que presenta los ejemplos de digitación también es diferente, sustituyendo las cifras de la primera edición por la expresión completa ("primer dedo", "segundo dedo", etc.).

Por otra parte, los dos primeros capítulos de esta edición de 1760 tratan, respectivamente, los elementos del lenguaje musical y los adornos, aspectos que no aparecían en la edición de 1750 y que derivan de los contenidos incluidos en la Anleitung de 1755. Ésta es, como se verá a continuación, la que se puede considerar como versión definitiva del texto.

Especial mención requiere la clasificación de los adornos musicales en Spielmanieren y Setzmanieren y su cuidadosa descripción, indicativa de la importancia que tenía la ornamentación en la interpretación musical a mediados del siglo XVIII. En los textos de la época es común la alusión a

20 "La buena respuesta con que el público ha acogido mi Arte de tocar el teclado me ha animado a proporcionarle con el presente escrito algo más completo sobre esta materia. Hay aficionados a los que les gusta tener reunido en un libro todo lo que concierne a cierto asunto. Pero aún hay más para los que no abundan las ventajas de una buena instrucción oral o que no pueden disfrutar suficientemente de ella. A ambos les satisfaraá esta Introducción". MARPURG, 1755: III. 
la necesidad de insertar adornos en la melodía. Así, el mismo F. W. Marpurg, afirmaba en otro texto que "ninguna composición agradaría a cualquier oído refinado sin la estricta observancia de los adornos" 21

Un año más tarde, en 1761, se publica en la imprenta de los herederos de Lotter en Augsburgo otra edición "ampliada" del tratado. No obstante, los añadidos a los que hace referencia el título lo son en relación con la primera edición de 1750 , y no respecto a la tercera edición de 1760 , por lo que el texto de Augsburgo puede considerarse una reimpresión de la publicación original, a la que los editores añaden algunas notas aclaratorias al pie. Además, como novedad, incorpora a lo largo del texto, en su lugar correspondiente, los ejemplos musicales que en el original aparecían en las cuatro tablas al final del tratado.

No obstante, hay muchos detalles hacen pensar que este volumen 1761 se trata de una edición no autorizada. En primer lugar, no aparece ninguna referencia a F. Marpurg; además, el prólogo no aparece firmado por el autor, sino por los editores. En él figuran ciertas afirmaciones que revelan cierto distanciamiento del autor:

"Der aus gegenwärtigenm Werke ohnfehlbar zu hoffende Nutz ist der eintzige Antrieb, die Kosten zu dessen wiederholter Auflage zu verwenden. Um es brauchbarer zu machen, hat ein Kenner dessen Fürtrefflichkeit die Mühe über sich nehmen wollen, einige Stellen mit Anmerkungen zu beleuchten: die zwar nicht allerdings nach seinem eignen Geschmack seynd [...]. Der Tittel scheint zwar zu versprechen, als lehrete das Werck die Kunst das Clavier zu spielen in ihrem ganzen Umfang: allein soll man darinn nicht mehr suchen, als einen vollständigen Unterricht von einer regelmäßigen und bequemen Fingersetzung. [...] Denen Clavezinisten die Finger nach der Regel und Bequemlichkeit einzurichten, ist das eintzige Absehen des Werckes [...]"22.

La alusión a los costes de una "nueva edición" hace pensar que ya anteriormente la imprenta de Lotter hubiera lanzado otra edición no autorizada de la obra. Por otra parte,

21 MARPURG, 1757: 2

22 "La utilidad que indudablemente se espera de la presente obra es el único incentivo para asumir los costes de esta nueva edición. Para hacerla más útil, un experto ha querido asumir el magnífico trabajo de ilustrar algunos pasajes con anotaciones, si bien no todas son de su agrado [...]. El título parece prometer que la obra muestre el arte de tocar el clave en su amplio espectro: sin embargo, no se puede pretender encontrar nada más que una enseñanza completa de la digitación regular y cómoda. [...] La única intención de esta obra es la guiar los dedos de los clavecinistas según la norma y la comodidad [...]". MARPURG, 1761a: 3 . este prólogo supone una crítica encubierta a los contenidos del tratado, por limitados ("no se puede pretender encontrar nada más que una enseñanza completa de la digitación regular y cómoda") y no completamente del agrado de los editores. A los tres ejemplares que cita RISM $^{23}$ de esta edición de Lotter, habría que añadir, al menos, el conservado en la Biblioteca Estatal de Baviera, bajo la signatura Mus.th.7157c.

Por otra parte, y paralelamente a las reediciones del tratado, F. Marpurg había redactado una segunda parte al mismo, dedicada a la enseñanza del acompañamiento al teclado $^{24}$. De nuevo, fue la imprenta de Haude y Spener la que se hizo cargo de esta publicación en 1761. Si bien no corresponde a este trabajo, dedicado a la primera parte del tratado, el estudio de las ediciones de su segunda parte, conviene únicamente mencionar la pronta difusión de que ésta gozó, con una traducción francesa ya en 1765, a cargo de Jacob Wilhelm Lustig (1706-1796), alumno de Mattheson y Telemann y organista en Gröningen ${ }^{25}$.

Ya en 1762, F. Marpurg encargó la cuarta edición de nuevo a la imprenta de Haude y Spener. Tal como se especifica en su subtítulo, se trata de una revisión corregida y aumentada ${ }^{26}$, si bien hay que aclarar que estas correcciones se dan respecto la primera edición de 1750 , pues en realidad no incorpora novedades respecto a la tercera edición de 1761 , de la que supone una mera reedición.

Por último, RISM ${ }^{27}$ cita la traducción francesa del tratado a cargo de Valentin Roeser (*1735c.; †1782c.) en 1764. Su título alude justamente a la "modernidad" de este texto: El arte de tocar el clavecín según la manera perfeccionada de los modernos. Por el sr. Marpurg [...] actualizado por el sr. Valentin Roeser siguiendo el consejo de los más grandes maestros y, particularmente, de la sra. Honaver y de Lee, que admiten su utlidad. Con una nueva manera de encordar el clavecín, fundada sobre la igualdad del temperamento, por el sr. Sorge ${ }^{28}$. Posteriormente, ya a finales de siglo, las imprentas parisinas de Naderman y Boyer publicaron sendas versiones del tratado, de las que apenas han llegado ejemplares a la actualidad.

Si bien las distintas ediciones y traducciones de El arte de tocar el teclado no se caracterizaron de forma general por ser fiel al original, su valor radica, precisamente, en la capacidad de "adaptación" del texto de F. Marpurg a un contexto musical cambiante. Así, al comparar las versiones sucesivas 
del tratado, conviene tener en cuenta el contexto histórico en que se gestaron, lleno de grandes cambios estéticos y técnicos para la interpretación de los instrumentos de tecla. De este modo, el estudio de la evolución de esta obra a través de sus consecutivas ediciones resultará de gran interés para comprender un momento clave de transición entre el gusto Barroco y la nueva forma de entender el arte.

\section{BIBLIOGRAFÍA}

Bernsdorf, Eduard (ed.): Neues Universal-Lexikon der Tonkunst: Für Künstler, Kunstfreunde und Gebildete. Dresden, Robert Schaefer, 1857, Vol. 2.

Couperin, François: L'Art de toucher le Clavecin. París, edición a cargo del autor y Foucault, 1716.

Eitner, Robert: Biographisch-Bibliographische QuellenLexicon der Musiker und Musikgelehrten. Leipzig, Breitkopf \& Härtel, 1902, Vol. 6.

Forkel, Johann Nikolaus: Musikalischer Almanach für Deutschland auf das Jahr 1782. Leipzig, Schwickert, 1782.

Gerber, Ernst Ludwig: Neues historisch-biographisches Lexikon der Tonkünstler. Leipzig, A. Kühnel, 1813. Vol. 3.

Hamberger, Georg Christoph y Meusel, Johann Georg: Das gelehrte Teutschland oder Lexicon der jetzlebenden Teutschen Schriftsteller. Lemgo, Meier, 1772.

Jördens, Karl-Heinrich: Lexikon deutscher Dichter und Prosaisten. Leipzig, Weidmann, 1809, Vol. IV.

Kuares, Yvonne: "Friedrich Wilhelm Marpurg und Halle". En Stöck, Stöck y Föllmerstöck, Gilbert, Stöck, Katrin, Föllmer, Golo (ed): Facta Musicologica: Musikgeschichten zwischen Vision und Wahrheit. Würzburg, Königshausen \& Neumann, 2003.

Lesure, François (dir.): Écrits imprimés concernant la musique. Vol. II (M-Z). Múnich-Duisburgo, G. Henle, 1971.

Marpurg, Friedrich Wilhelm: Des critischen Musicus an der Spree erster Band. Berlín, A. Haude y J. C. Spener, 1750.

Marpurg, Friedrich Wilhelm: Die Kunst das Klavier zu spielen, durch den Verfasser des Critischen Musicus an der Spree. Berlín, Henning, 1750.

Marpurg, Friedrich Wilhelm: Die Kunst das Klavier zu spielen. Berlín, Haude und Spener, 1751.
Marpurg, Friedrich Wilhelm: Anleitung zum Clavierspielen nach der schönern Ausübung der heutigen Zeit. Berlín, A. Haude und J. C. Spener, 1755.

Marpurg, Friedrich Wilhelm, (ed.): Historisch-kritische Beyträge zur Aufnahme der Musik. Berlín, Gottlieb August Lange, 1757, Vol. 3.

Marpurg, Friedrich Wilhelm: Die Kunst das Klavier zu spielen, durch den Verfasser des Critischen Musicus an der Spree. Dritte, verbesserte und vermehrte Auflage. Berlín,

A. Haude und J. C. Spener, 1760.

Marpurg, Friedrich Wilhelm: Die Kunst das Klavier zu spielen, durch den Verfasser des Critischen Musicus an der Spree. Augsburgo, herederos de Johann Jacob Lotter, 1761.

Marpurg, Friedrich Wilhelm: Die Kunst das Klavier zu spielen. Zweyter Theil, worinnen die Lehre vom Accompagnement abgehandelt wird. Berlín, A. Haude y J. C. Spener, 1761.

Marpurg, Friedrich Wilhelm: Die Kunst das Klavier zu spielen, durch den Verfasser des Critischen Musicus an der Spree. Vierte, verbesserte und vermehrte Auflage. Berlín, A.Haude und J. C. Spener, 1762.

Marpurg, Friedrich Wilhelm: L'art de toucher le clavecin selon la manière perfectionée des modernes. (...) mis au jour par M. Valentin Roeser (...) d'après le conseil des plus grands maîtres, et particulièrement de Mrs Honaver et Lee qui en reconnoissent l'utilité. Avec une nouvelle manière d'accorder le clavecin, fondée sur l'égalité du tempérament, par M. Sorge (...). París, Le Menu, [1764].

Marpurg, Friedrich Wilhelm: L'art de joüer le clavessin. Seconde partie, qui contient les principes de l'accompagnement (...) par Frédéric Guillaume Marpurg (...) Traduit de l'allemand par Jaques Guillaume Lustig. Aanleiding tot her clavierspeelen. Het tweede deel (...) door Fridrich Wilhelm Marpurg (...) Uit her hoogduitsche vertaald door Jacob Wilhelm Lustig. Amsterdam, J. J. Hummel, [1765].

Meusel, Johann Georg: Lexikon der vom Jahr 1750 bis 1800 verstorbenen teutschen Schriftsteller. Leipzig, Gerhard Fleischer "el joven", 1808, Vol. 8. 

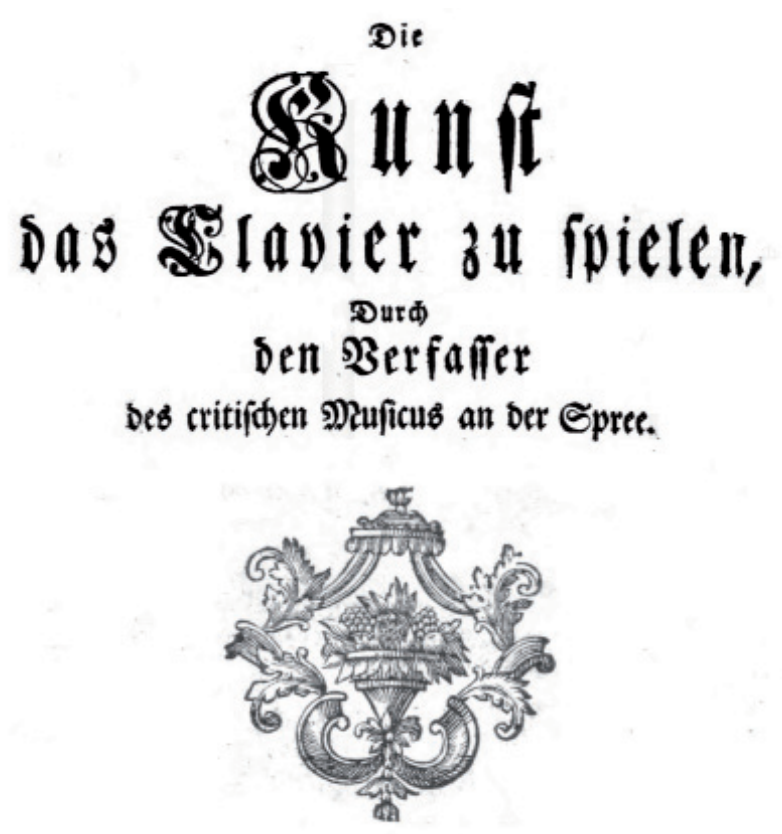

Bettin, gebruct mit Đenningifden Edriften.

7 . 5 .

\section{El arte de tocar el teclado, \\ por el autor de El músico crítico junto al río Esprea.}

Berlín, impreso con caracteres de Henning.

1750 . 
Al ilustrísimo ${ }^{1}$ señor Christlob Mylius.

Señor mío:

No debe ser sino infundado el reproche que se les hace a las ciencias más puras de tratar de hacer indiferente e insensible la sensibilidad de sus adeptos hacia las Bellas Artes, y sobre todo a la música. Quizás estos huraños estudiosos, que desprecian el sonido de un instrumento, deban atribuir su desafortunado destino más a su estado de ánimo interno que a las dificultades de sus ocupaciones habituales. Mediante el ejemplo de un inestimable amigo, me alegra poder liberar a las ciencias puras de prejuicio tan contrario a ellas. Señor mío, usted no sólo ama el arte sonoro y se deleita escuchando un buen concierto. Usted es capaz de deleitar amablemente al teclado con sus propios dedos. Quizás no hubiera tenido la valiosa suerte de conocerle si la música no hubiera intermediado. A ésta le debo el beneficioso placer que disfruto diariamente en presencia de usted. También me considero suficientemente autorizado para dedicarle el presente trabajo. Asimismo, por una vez querría darle públicamente las gracias por sus muchas pruebas de la más sincera amistad. Aun así, al menos pretendo saldar mi deuda con usted, de modo que, si le agradaran estas páginas, encuentre una nueva oportunidad para responderle con aún mayor obligación y admiración.

De mi señor, el más obediente servidor, el autor.
Prólogo.

Gentil lector,

Te entrego con esto un pequeño escrito, del que tienes muy poco que agradecerme aparte de la preocupación. Quizá conozcas el nombre de Couperin. Lo he utilizado como base. Que no te frene el que sea francés. Si hubiera encontrado a un italiano que hubiera escrito bien sobre el arte de tocar el teclado, también hubiera compartido sus ideas. Los clavecinistas italianos todavía no han demostrado hasta hoy, a pesar de sus admiradores incondicionales, que su ejemplo deba servir como modelo en la técnica de teclado. Como alabanza de Couperin no puedo añadirte sino que los estudiosos de Bach lo consideran igualmente digno de su gusto. Debo mencionar en este punto que no he seguido a este hombre de principio a fin, palabra a palabra. Aquí y allá me han venido mis propios pensamientos y ejemplos. Como también me han servido de consejo otros escritores y he dialogado con algunos virtuosos, sobre todo con nuestro reverenciado Bach, en algunos puntos la obra se ha extendido ligeramente. Sobre todo, me he servido de la digitación de algunas escalas según el método fundado por este hombre. Todo esto lo he hecho con la intención de ponerte en las manos un tratado tan poco incompleto como sea posible. Si tiene la fortuna de obtener tu beneplácito, esto me animará a ofrecerte algunas breves suites para tecla expresamente escritas para la mecánica de los dedos.

Quedo a la completa disposición del gentil lector, el autor.

1 Originalmente, este título servía para dirigirse a alguien de alto rango pero sin origen noble. 


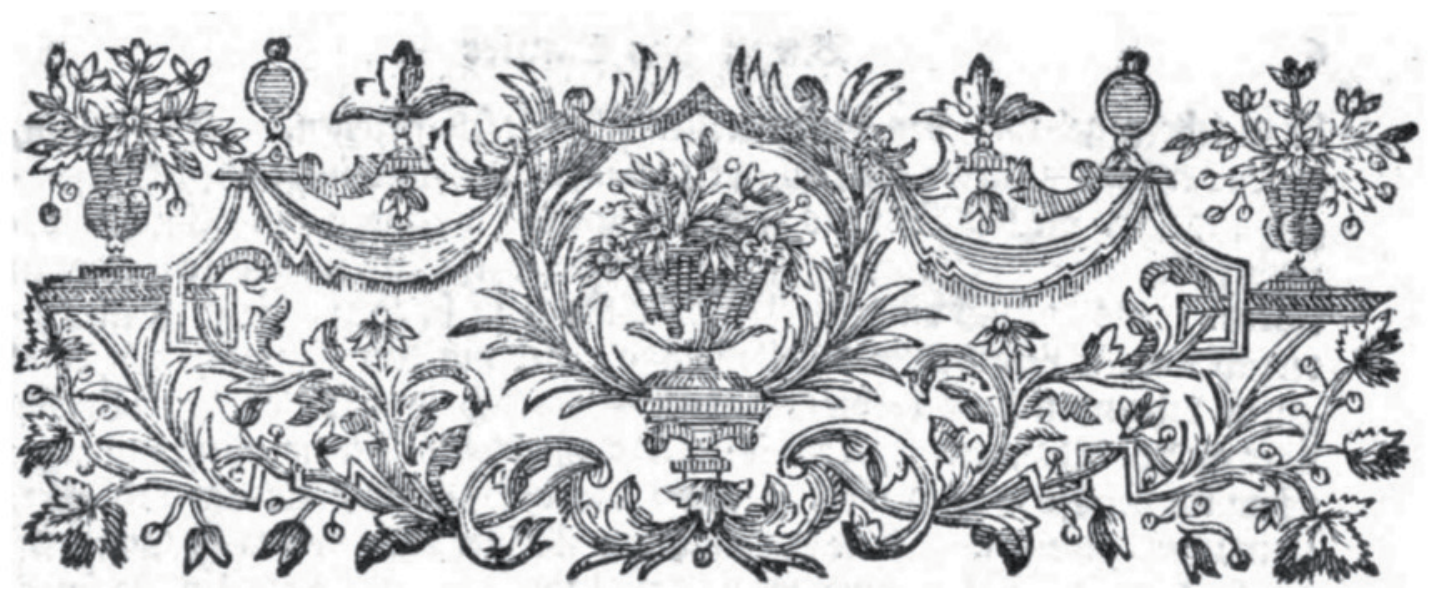

\section{§.1.}

La edad más apropiada para comenzar a tocar el teclado está entre el sexto y el séptimo año, no por excluir a personas mayores, sino porque en este momento se puede acostumbrar con mayor facilidad a las manos en el ejercicio mecánico del teclado de forma más natural.

\section{§.2.}

Entre las características del aprendiz corresponde no sólo un juicio y unos miembros sanos, esto es, un buen oído y un puño [mano] articulado, sino también un carácter moldeable y dispuesto a recibir con curiosidad y atención las enseñanzas musicales. El maestro no puede hacer más que indicarnos el camino hacia la obra. Es nuestra culpa si no podemos o queremos ponerla en práctica.

\section{$\S .3$.}

Elíjase como maestro a uno que tenga fama de tener alumnos hábiles. Aquéllos que mejor tocan no son siempre los mejores maestros, así como tampoco los buenos compositores son los mejores intérpretes, y viceversa: quienes dan vida a las obras tampoco son los más grandes compositores. No es grande la cantidad de personas que reúnen las tres habilidades con cierto grado de perfección. Hay virtuosos que tienen a los peores alumnos, y hay intérpretes mediocres que tienen la habilidad de enseñar y atraen al más conocido virtuoso. Aquéllos que deben su arte a los mejores tratados no son siempre los mismos que son capaces de embelesar al oído del entendido con los sonidos más agradables. Emocionar a alguien es diferente a enseñar. Así, hay que considerar afortunada a la persona que logra que le dé clase un maestro que una éstas a las características del buen aprendiz, de modo que al tocar también aventaje al resto. Además de esto, el maestro debe poseer un carácter generoso, y no trabajar por dinero, sino por prestigio. Los maestros egoístas frenan a uno tanto como pueden. Les importa menos el avance de su alumno que el suyo propio. Retrasan para mañana lo que podrían enseñar hoy. Ocultan los golpes maestros. Si el alumno les plantea una pregunta, no colman su curiosidad. O no dan respuesta, o la dan de forma tan confusa que nadie la puede entender. No corrigen las faltas de sus alumnos. Su progreso, su ambición por llegar siempre más allá, les hace desconfiados. El buen maestro generoso procura hacer a la persona que confía en él más perfecta que a sí mismo. Su crecimiento le causa alegría, y no busca tener muchos alumnos, sino pocos y buenos.

\section{$\S .4$.}

Pero si se tiene la suerte de encontrar a un maestro íntegro y hábil, también se está obligado a pagarle con generosidad por su dedicación. Muchos consideran a quien exige lo suyo como a una persona que no sabe vivir. Le pagan miserablemente durante un mes y creen que obran bien cuando hacen la jugada de despedir al maestro y elegir a otro que, según su opinión, tiene mayor estatus. Nada es más perjudicial para el avance de un alumno que cambiar de maestro. 


\section{$\S .5$.}

Al principio, para personas muy jóvenes, sírvase como instrumento de un simple teclado, una espineta o un único registro del teclado, y en este último instrumento obsérvese que los plectros estén ajustados muy débilmente. Este punto es muy importante, pues la buena interpretación o ejecución depende más de la flexibilidad de unos dedos dúctiles e independientes que de la fuerza; y si se hace a un niño tocar en un teclado emplectrado con firmeza, necesariamente tendrá que esforzar sus tiernas manos con gran presión para pulsar las teclas. Y es de aquí que surge el toque áspero y duro, así como la mala posición de las manos.

\section{\$.6.}

Manténganse las manos rectas sobre el teclado. Los dedos han de estar curvados y sus puntas deben dibujar una línea horizontal con los codos y la base del pulgar. Esto depende de la correcta postura del cuerpo, y para conseguirla, hay que elegir una silla cómoda.

\section{$\S .7$.}

La distancia entre el cuerpo y el teclado es de entre seis y diez pulgadas², según la persona tenga los brazos más largos o más cortos.

\section{$\S .8$.}

Siéntese justo en el centro del teclado, para que ambas manos puedan alcanzar las teclas más alejadas sin dificultad y no se esté obligado a moverse del sitio a cada momento o a saltar con el cuerpo.

\section{$\$ .9$.}

Cuando se esté ante el teclado, gírese el cuerpo ligeramente hacia el lado derecho. No se junten excesivamente las rodillas. Colóquense los pies uno junto al otro, y manténgase el pie derecho ligeramente hacia delante.

\section{\$. 10.}

Para que los pies de los más jóvenes no cuelguen en el aire y el cuerpo se mantenga en el equilibrio correcto, procúrese que dispongan de una banqueta más baja o más alta de acuerdo a su altura, o un escabel bajo sus pies.

\section{§. 11.}

Las personas que empiezan tarde o a las que algún burdo "zapatero" ha perjudicado con enseñanzas incorrectas, tengan en cuenta que, como los nervios ya han podido endurecerse algo, o también haber adquirido un vicio inapropiado, antes de sentarse al teclado pueden estirarse los dedos o hacer que alguien se los estire. Esto hace que los ánimos se pongan en acción. De este modo, los dedos se vuelven más flexibles e independientes.

\section{$\S .12$.}

Las personas de género masculino que quieran alcanzar cierto grado de habilidad, deberían evitar cualquier tipo de tarea manual severa. Por eso las manos de las mujeres son siempre mejor.

\section{§.13.}

Las manos han de mantenerse a la misma altura una junto a la otra sobre el teclado. Si alguien mantiene una [mano] demasiado alta al tocar, el mejor remedio es que se haga a alguien sujetar un bastón flexible de la longitud correspondiente sobre la mano que comete este error, mientras, al mismo tiempo, pasa por debajo de la otra mano. Si esta persona mantiene la mano demasiado baja, hágase al contrario. Pero no hay que golpear con este palo a la persona que toca. Poco a poco irá corrigiéndose el error.

2 Es decir, de entre 15 y $25 \mathrm{~cm}$ aproximadamente. 


\section{$\S .14$.}

Levántense los dedos rápidamente en cuanto termine el valor de las notas. No se hagan movimientos violentos ni saltos temerarios al aire con las manos. Es fácil pasar por alto, si no se tiene experiencia, que una mano que cae desde arriba produzca un golpe más fuerte que cuando se encuentra cerca del teclado y, por tanto, las cuerdas respondan con un sonido más duro y áspero. Hay que mantener los dedos tan firmemente sobre las teclas como sea posible. Pero al mismo tiempo que hay que tener cuidado con los golpes fuerte sobre las teclas, tampoco hay que deslizarse sobre ellas con tanta indolencia que las cuerdas no produzcan el sonido correspondiente. Para acostumbrar a las personas a las que se enseña, al principio se les puede poner un trocito de plomo sobre las manos. Si éste se mantiene, es señal de que el movimiento es equilibrado.

\section{$\S .15$.}

Por lo que respecta a los gestos y muecas, no hay método mejor para corregirlas que colocarse un espejo delante en el atril y juzgar después. Entre los vicios al tocar también está la costumbre de algunas personas de marcar el compás con la cabeza, con el pie o con todo el cuerpo. Si alguien no puede mantener el pulso sin mover los pies, al menos hay que hacerlos imperceptibles al oído de los demás.

\section{$\S .16$.}

En las primeras horas de instrucción no es aconsejable mantener a los niños en ausencia de la persona que les instruye para practicar la lección. Los jóvenes son demasiado despreocupados como para preocuparse por mantener las manos en la posición que se les ha indicado. Con una repetición viciada pueden destruir en un momento lo que un maestro hábil ha construido con cuidado durante un tiempo de tres cuartos de hora.

\section{$\S .17$.}

Acostúmbrese a encontrar rápidamente las teclas para no estar obligado a cada momento a dirigir los ojos al piano y de nuevo hacia atrás cuando se toque con partitura.

\section{$\S .18$.}

Sin embargo, no se debe comenzar deteniendo a los niños en el exacto conocimiento del teclado ni hacerles leer del papel hasta que no les queden ejercicios preparatorios. Es casi imposible que, si deben dirigir los ojos hacia las notas, sus dedos no se confundan desordenados, y que los ornamentos no salgan perjudicados con ello. Al principio, hágales estudiar todo de memoria. Es muy importante la honradez y la delicadeza al tocar, casi más que el arte de acertar [las notas]; y, al fin y al cabo, dos o tres meses arriba o abajo tampoco suponen nada. Además, hay que hacer que el niño toque la partitura con una mano antes de dejarle tocar con las dos juntas.

\section{§.19.}

Algunos maestros acostumbran a abrumar a sus alumnos ya desde el comienzo con lecciones y ejercicios complicados. Argumentan que, si dominan lo difícil, harán lo fácil sin dificultad. Esta opinión es errónea. Todo depende del tiempo y de la práctica. Es imposible que, si ya al comienzo no se sabe qué se hace, se aprenda más adelante. Además, al alumno le resulta agradable que le den cosas que pueda aprender fácilmente. Esto aumenta su interés por estudiar. Poco a poco y, por así decirlo, en broma, se le conduce a cosas más difíciles, y por último a las de mayor dificultad. Pero las lecciones difíciles dadas antes de tiempo pueden acobardar hasta el ánimo más despierto.

\section{$\S .20$.}

Al principio, guárdese también de tocar rápido. Éste es el primer paso hacia la falta de claridad y el caos. Y suele confundir el orden de los dedos.

\section{$\S .21$.}

Esfuércese en hacer que todos los dedos indistintamente sean igual de flexibles con los ejercicios necesarios para ello. No deben excluirse ni el meñique ni el pulgar. Se puede afirmar con seguridad que los maestros que excluyen a ambos [dedos] de la digitación, están echando a perder a sus pupilos. Incluso se me asemeja a alguien que quisiera arrancarse un par de dientes o cortarse un trozo de la lengua para cantar bien. Si se tuvieran más dedos todavía, se podrían usar todos. 


\section{§.22.}

No hay duda de que las frecuentes arias para canto que se hacen tocar al alumno en el teclado no sirven para que obtenga con ellas una especial habilidad, especialmente en la mano izquierda. No hace falta advertir que son muy preferibles las piezas escritas por grandes maestros específicamente para teclado, a las piezas transcritas del canto, del violín, de la flauta o de otros instrumentos.

\section{$\S .23$.}

No se pase ninguna lección hasta que no se sepa tan bien como sea posible. El desarrollo de un alumno no se juzga por la cantidad de piezas, sino por la habilidad de tocarlas correctamente.

\section{$\S .24$.}

Más que tocar, muchos pellizcan los acordes, según el buen gusto italiano. Nótese que deben percutir con los dedos y no con la mano rígida, es decir, que el movimiento de los dedos debe ser independiente del movimiento de la mano, y este movimiento debe contribuir a la conexión que independiza los dedos de la mano.

\section{$\S .25$.}

Al no tener los habituales adornos "tocados", de los que se encontrará una prolija descripción en El músico crítico junto al Esprea, hágase que el principiante toque todo tipo de adornos "escritos", pues se le deben prescribir como entrenamiento de los dedos3. Comiéncese por los más sencillos en las tonalidades más fáciles. Lléveles poco a poco hacia los más difíciles y déles estos mismos ejemplos en las tonalidades transportadas. Estos pequeños ejercicios, que no habrán de repetirse demasiado, son todos los materiales que pueden emplearse durante este tiempo en determinados lugares de muchas maneras. Daremos algunos modelos de ello, a partir de los que se podrán deducir otros a placer.

\section{$\S .26$.}

El modo de guiar y alternar los dedos contribuye en gran medida al arte de interpretar, pues es cierto que una melodía expresada de uno u otro modo genera una reacción diferente al oído de alguien con gusto. Así, como una combinación de ambos es lo mejor, se puede deducir fácilmente, por tanto, que la digitación no es algo caprichoso. Es cierto que muchos pasajes pueden hacerse de más de una manera. Hemos dado ejemplos de ello en nuestra digitación. Sin embargo, por otra parte, también hay muchas ocasiones en las que todos los que tocan tienen que usar justo los mismos dedos, si quieren interpretar éste o aquél pasaje cómodamente y con limpieza, lo cual es lo que más debe cuidarse, junto a la postura. En general, siempre hay que preferir los cambios de dedos que provocan el mínimo movimiento de la mano. En esto, obsérvese constantemente la siguiente nota, de modo que se ordenen los dedos correspondientes en previsión. Esta regla merece especial atención.

\section{$\S .27$.}

Hay que evitar utilizar un dedo y otra vez el mismo de forma consecutiva, especialmente en pasajes rápidos. En las planchas de cobre que siguen daremos algunos ejemplos de pasajes en los que sí procede.

\section{$\S .28$.}

Mucha gente no es capaz de ejecutar un trino o una apoyatura con la misma habilidad en unos dedos que en otros. A estas personas corresponde practicar ya desde el principio preferentemente con los dedos malos. Los dedos para dichos adornos son el segundo con el tercero en la mano derecha y el tercero con el cuarto. Algunos acostumbran a trinar con el segundo y cuarto dedo o con el tercero y quinto entre Mi y Fa sostenido, o entre Si y Do sostenido, sobre todo en teclados duros. En la mano izquierda, se sirven del pulgar con el segundo dedo, y del segundo con el tercero. Aquí hay que tener en cuenta que algunos acostumbran a invertir el La con el Si bemol y el Re con el Mi bemol, tocando el La o el Re con el pulgar y la nota

3 La clasificación más amplia de los adornos es la distinción que algunos autores establecen entre Spielmanieren (o adornos "tocados") y Setzmanieren (o adornos "escritos"). Así, mientras que estos últimos aparecen desarrollados por el compositor como parte del discurso musical y consisten en la atomización del tiempo correspondiente al valor "real" más largo, en ritmos más breves, las Spielmanieren consisten en la inserción de adornos, tanto improvisados por el ejecutante como escritos de forma abreviada por el compositor. 
contigua Si bemol o Mi bemol con el segundo dedo. Ésto depende de la comodidad para cada cual. Si no se tiene necesidad de hacer los trinos y las apoyaturas con los dedos habituales de forma ordenada, entonces está bien practicarlos también de este modo; más aún si, entre las voces que siguen su curso, se quiere seguir batiendo el trino denominado de terceras o a dos voces.

\section{$\S .29$.}

Al indicar los dedos, hay que tener en cuenta que en ambas manos señalaremos el pulgar con la cifra 1, al que sigue con el 2, al dedo medio con el 3, al que sigue con el 4 y al meñique con el 5. Cuando hay dos cifras junto a una nota, o encima, o debajo, con ellas se indica que existe más de una posibilidad de digitación. Tómense aquí los ejemplos donde aparecen dos claves en un sistema, en los que las cifras encima y debajo de las notas se refieren a la mano derecha e izquierda [respectivamente]. Cuando aparecen dos cifras juntas y un pequeño guión entre ambas, encima o debajo de una nota, con ello se indica que los dedos que se indican deben intercambiarse, con la salvedad de que si la cifra más grande es la primera, a continuación se debe subir, y si la más pequeña es la primera, se debe bajar a continuación. Este cambio de dedos en una misma nota sirve para que la interpretación sea más fluida y para que una nota no se interrumpa, sino para que se conecte estrechamente a la siguiente.

\section{$\S .30$.}

En la elección de dedos en melodías polifónicas, hay que observar la propiedad de las circunstancias en aquellos acordes que pueden digitarse de más de una manera, así como en la comodidad para cada persona, según tenga dedos largos o cortos. Nótese aquí que no hay ninguna otra [digitación] buena posible, aparte de la digitación que se ha señalado. Hablemos de cada mano por separado. 
(I) De los acordes con la mano derecha.

\section{Y en primer lugar, concretamente, en melodías a dos voces. Aquí hay que observar}

1) Si el acorde abarca un intervalo de segunda. En este caso hay que servirse del segundo con el tercer dedo y del tercer con el cuarto dedo. Por ejemplo:

$\begin{array}{llllll}3 & \text { a } & \mathbf{4} & 3 & \mathrm{La} & 4 \\ \mathbf{2} & \mathfrak{g} & \mathbf{3} & 2 & \mathrm{Sol} & 3\end{array}$

Pero también pueden darse casos en los que este acorde se toque con los dos primeros dedos o con los dos últimos, en concreto cuando deba mantenerse y arriba o abajo se complete con algunas notas. Véase Tabla I, No. 4.

2) Si el acorde abarca el intervalo de una tercera, por ejemplo:

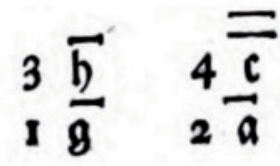
$5 \frac{\bar{D}}{3}$
3 'Si
4 "Do
5 "Re
1 'Sol
2 'La
3 'Si

En ocasiones deben tomarse los dos primeros o los dos últimos dedos. Véase Tabla I, No. 5. Para el modo de hacer terceras consecutivas, véase Tabla III, No. 8 .

3) Si el acorde abarca un intervalo de cuarta, quinta o sexta, por ejemplo:

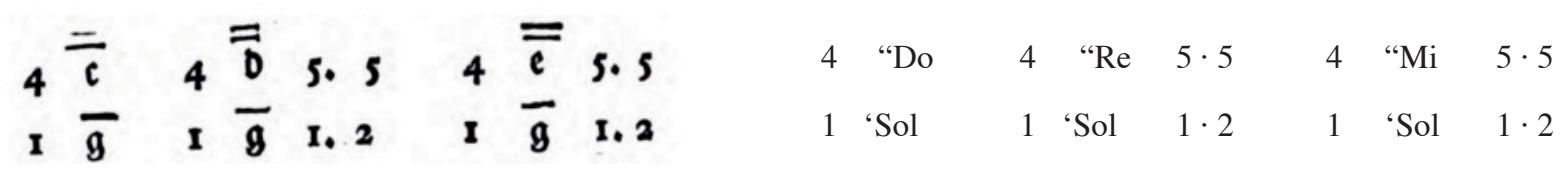

Si debe hacerse un trino sobre la nota superior, éste debe tocarse con el tercer dedo siempre que el trino no pueda hacerse con los dos últimos dedos.

4) Si el acorde abarca un intervalo de séptima u octava, por ejemplo:

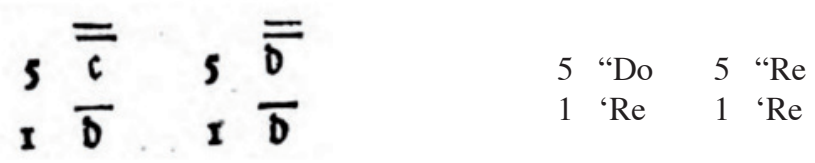

Las personas que tienen los dedos muy largos suelen tocar las dos notas a distancia de séptima con los dedos índice y meñique. Sin embargo, este modo es, en primer lugar algo forzado y, por tanto, no es común. Aun así, puede darse en ciertas ocasiones, de las que hablaremos más abajo. 
En segundo lugar, de las melodías a tres voces.

Aquí cabe preguntarse de nuevo

1) Si el acorde está comprendido en un intervalo de cuarta. Por ejemplo:
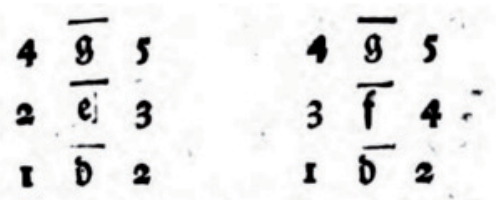
4 'Sol 5
2 'Mi 3
$1 \quad \operatorname{Re} 2$
Sol 5
$3{ }^{\prime} \mathrm{Fa} \quad 4$
$1 \quad \operatorname{Re} 2$

En ocasiones deben tomarse en el primer ejemplo los tres últimos dedos [el segundo grupo de digitación, indicado a la derecha de las notas] y en el segundo los tres primeros. Véase Tabla I, No. 6.

2) Si está comprendido en un intervalo de quinta, por ejemplo:

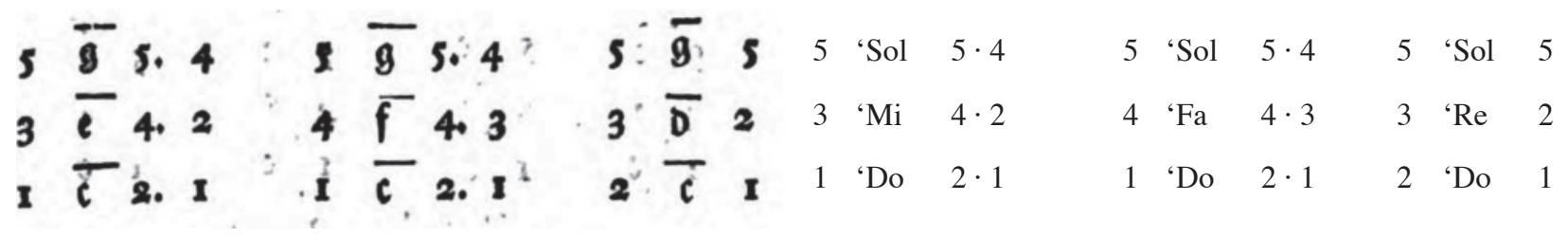

Si en este acorde los intervalos están a distancia de tercera, como

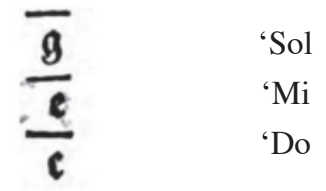

algunos suelen usar los dedos segundo, tercero y meñique. Esta digitación es errónea, y no debe imitarse para nada.

3) Si está comprendido en un intervalo de sexta, por ejemplo:

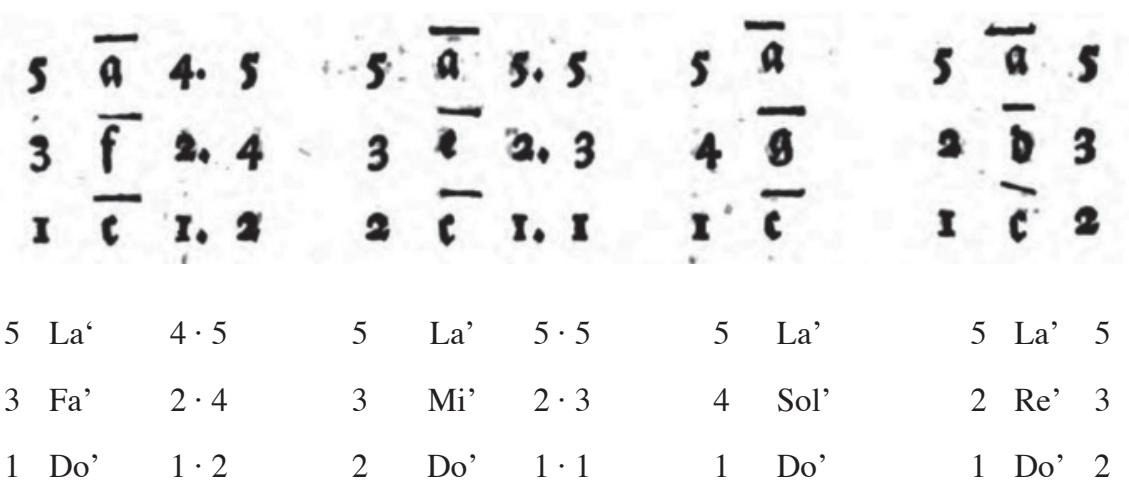


Algunos también suelen usar la digitación defectuosa antes citada en frases a tres voces en las que la [voz] central está a distancia de cuarta de la inferior, y a distancia de tercera de la superior, como en

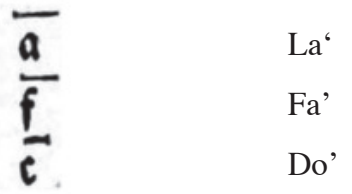

Evítese una digitación tan mala.

4) Si el acorde está comprendido en un intervalo de séptima, por ejemplo:

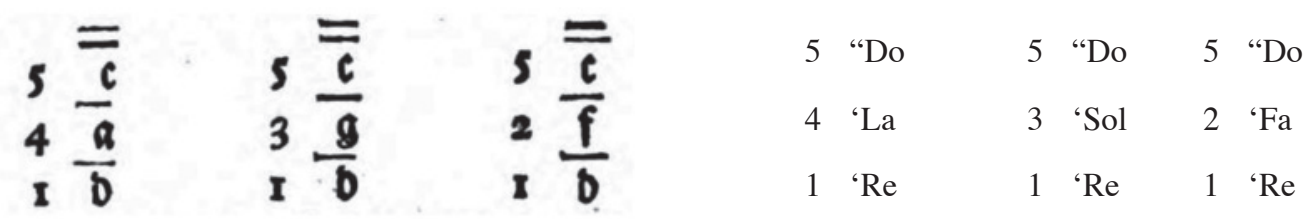

5) Si al principio está contenido en una octava, por ejemplo:

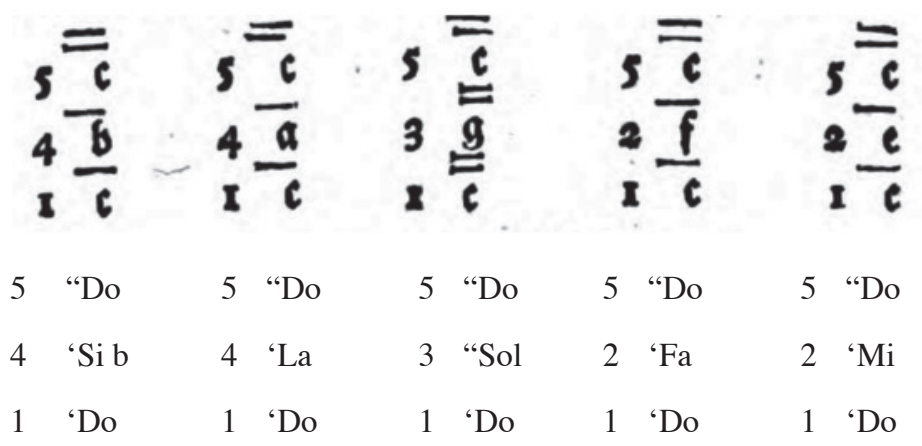


En tercer lugar,

de las melodías a cuatro voces.

Obsérvese aquí

1) Si el acorde está comprendido en un intervalo de quinta, por ejemplo:

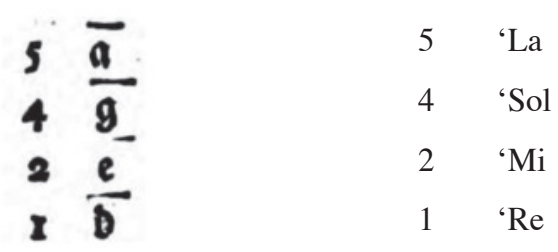

2) Si está comprendido en un intervalo de sexta, por ejemplo:
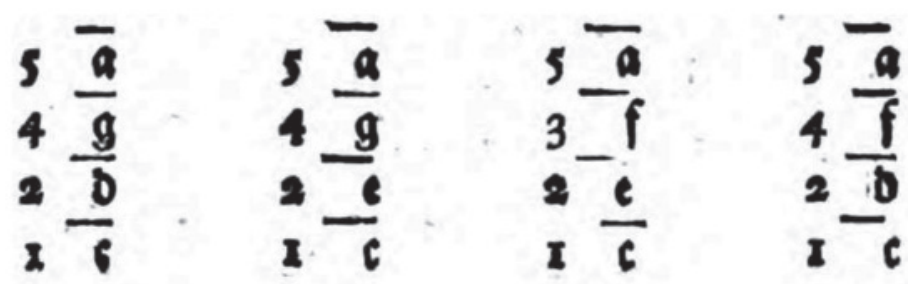

\begin{tabular}{|c|c|c|c|}
\hline $5{ }^{\prime} \mathrm{La}$ & $5{ }^{\prime} \mathrm{La}$ & 5 & ' $\mathrm{La}$ \\
\hline 4 'Sol & 4 'Sol & 3 & ' $\mathrm{Fa}$ \\
\hline $2{ }^{\prime} \operatorname{Re}$ & $2{ }^{\prime} \mathrm{Mi}$ & 2 & 'M \\
\hline 1 'Do & 1 'Do & 1 & $\mathrm{D}$ \\
\hline
\end{tabular}

3) Si está comprendido en un intervalo de séptima, por ejemplo:

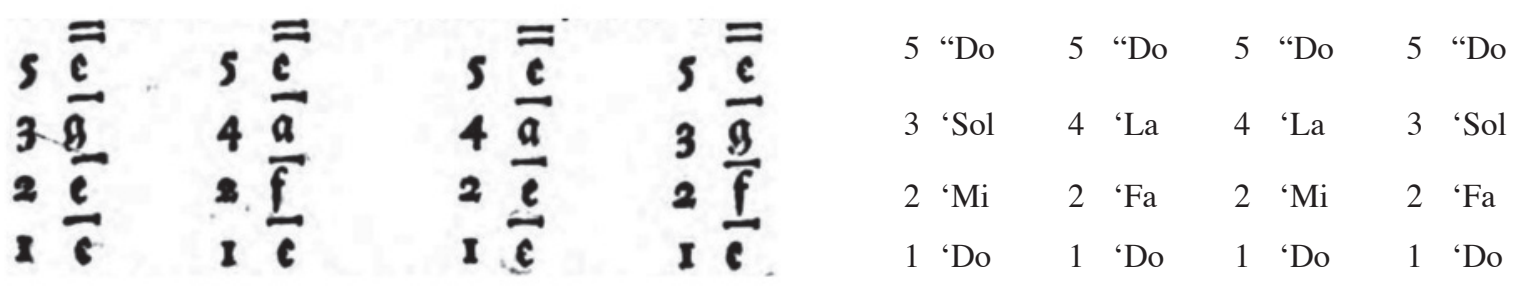


4) Si está comprendido en un intervalo de octava, por ejemplo:

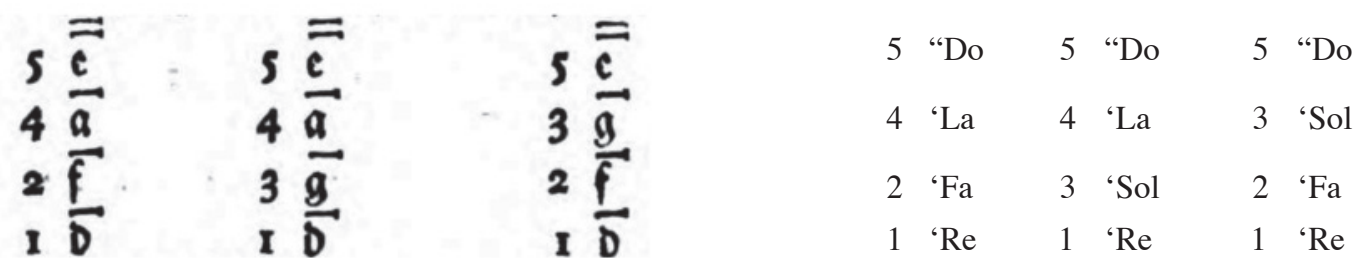

(2) Sobre los acordes con la mano izquierda y en primer lugar, concretamente, en melodías a dos voces.

Obsérvese aquí

1) Si ambas notas forman una segunda. En este caso, sírvase de los dos primeros dedos, o del segundo y el tercero, por ejemplo:

$$
\begin{array}{llllll}
\boldsymbol{1} & \mathbf{2} & \mathbf{2} & 1 & \mathrm{Mi} & 2 \\
2 & \mathbf{1} & \mathbf{3} & 2 & \mathrm{Re} & 3
\end{array}
$$

Pero también pueden usarse los demás si el acorde se mantiene y si debe completarse hacia arriba con algunas notas. Véase Tabla I, No. 7.

2) Si ambas notas conforman una tercera, por ejemplo:

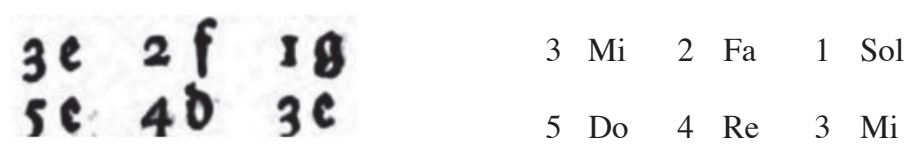

En ocasiones deben usarse los dos primeros [dedos] o los dos últimos. Véase Tabla I, No. 8.

3) Si ambas notas forman una cuarta, quinta o sexta, por ejemplo:

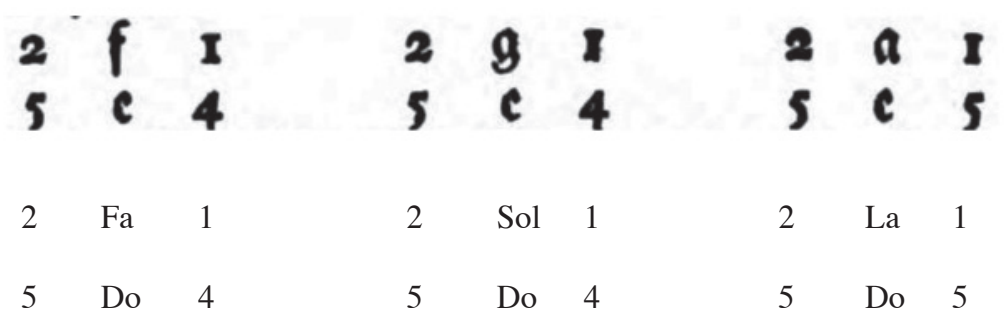

4) Si ambas forman una séptima u octava, por ejemplo:

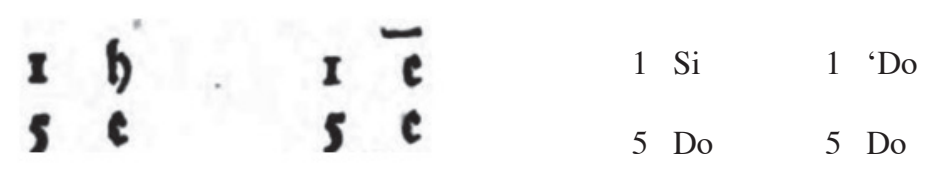


En segundo lugar,

de las melodías a tres voces.

Aquí la cuestión es

1) Si el acorde está contenido en un intervalo de cuarta, por ejemplo:
$\begin{array}{lll}2 & 9 & 1 \\ 3 & f & 2 \\ 5 & 0 & 4\end{array}$
$\begin{array}{ll}\text { I } & 8 \\ 3 & \text { e } \\ 4 & 5\end{array}$
2 Sol 1
1 Sol
$3 \mathrm{Fa} \quad 2$
$3 \mathrm{Mi}$
$5 \operatorname{Re} 4$
$4 \operatorname{Re}$ I, No. 9 .

En ocasiones, en el primer ejemplo deben tomarse los tres últimos dedos y, en el segundo, los tres primeros. Véase Tabla

2) Si está contenido en un intervalo de quinta, por ejemplo:

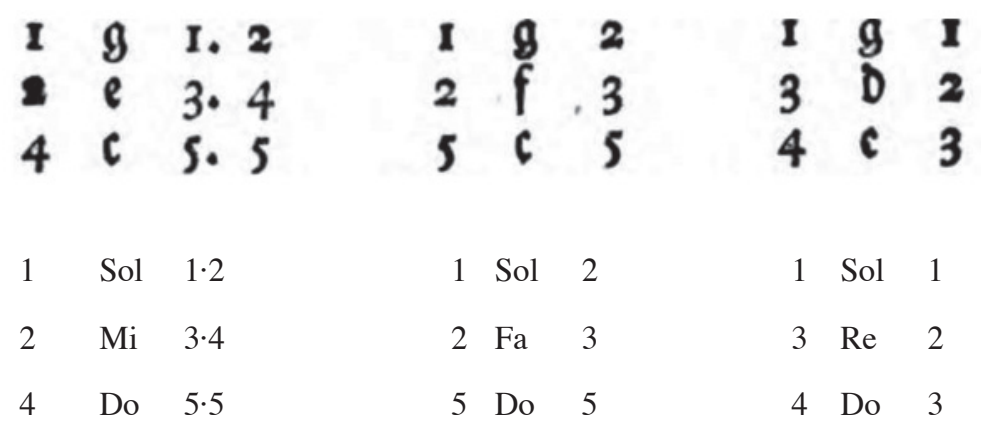

3) Si está contenido en un intervalo de sexta, por ejemplo:

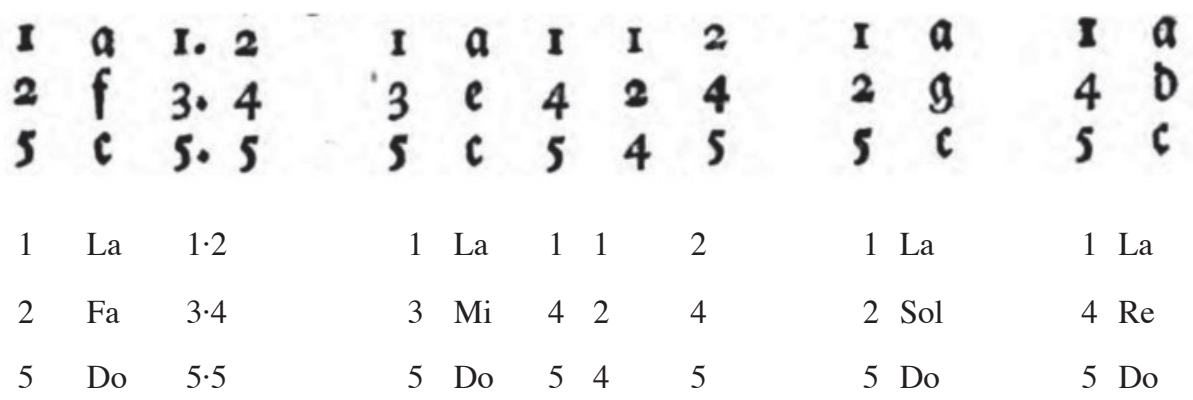

4) Si está contenido en un intervalo de séptima, por ejemplo:
2 i
$\begin{array}{lll}1 & f & 1 \\ 2 & C & 3 \\ 5 & 8 & 5\end{array}$
$\begin{array}{lll}\text { I } & \text { f } & \text { I } \\ 3 & b & 4 \\ 5 & 9 & 5\end{array}$
$\begin{array}{llllllll}1 & \mathrm{Fa} & 1 & \mathrm{Fa} & 1 & 1 & \mathrm{Fa} & 1\end{array}$
$\begin{array}{llllllll}2 & \operatorname{Re} & 2 & \mathrm{Do} & 3 & 3 & \mathrm{Si} & 4\end{array}$
$5 \mathfrak{g}$
$\begin{array}{llllllll}5 & \text { Sol } & 5 & \text { Sol } & 5 & 5 & \text { Sol } & 5\end{array}$ 
5) Si está contenido en un intervalo de octava, por ejemplo:

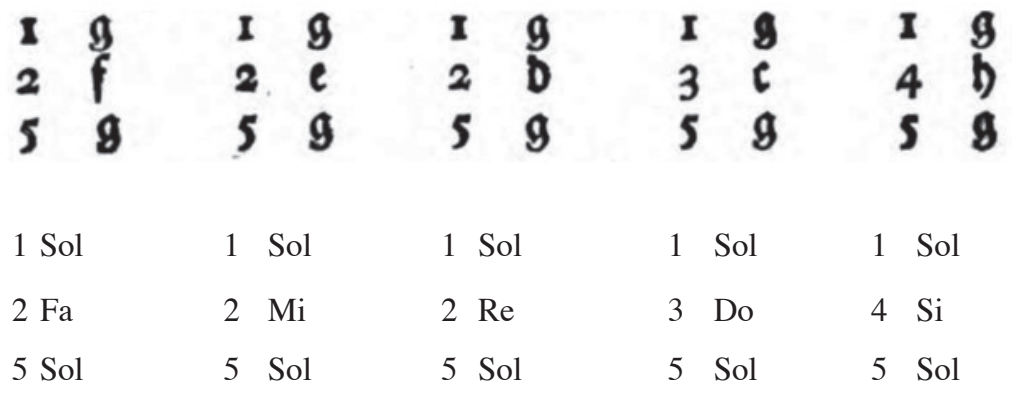


En tercer lugar,

de las melodías a cuatro voces.

Obsérvese

1) Si el acorde está contenido en un intervalo de quinta, como por ejemplo:

$\begin{array}{llll}\mathbf{I} & \mathbf{g} & 1 & \mathrm{Sol} \\ \mathbf{2} & \mathbf{f} & 2 & \mathrm{Fa} \\ \mathbf{4} & \mathbf{b} & 4 & \mathrm{Re} \\ \mathbf{5} & \mathrm{C} & 5 & \mathrm{Do}\end{array}$

2) Si está comprendido en un intervalo de sexta, por ejemplo:

$\begin{array}{lllllllllllllll}\mathbf{I} & \boldsymbol{a} & \mathbf{I} & \boldsymbol{a} & \mathbf{I} & \mathbf{a} & \mathbf{I} & \boldsymbol{a} & 1 & \mathrm{La} & 1 & \mathrm{La} & 1 & \mathrm{La} & 1 \mathrm{La} \\ \mathbf{2} & \mathbf{f} & \mathbf{2} & \mathbf{f} & \mathbf{2} & \mathbf{g} & \mathbf{2} & \mathbf{g} & 2 & \mathrm{Fa} & 2 & \mathrm{Fa} & 2 & \mathrm{Sol} & 2 \mathrm{Sol} \\ \mathbf{4} & \mathbf{b} & \mathbf{3} & \mathbf{e} & \mathbf{4} & \mathbf{e} & \mathbf{4} & \mathbf{b} & 4 & \mathrm{Re} & 3 & \mathrm{Mi} & 4 & \mathrm{Mi} & 4 \mathrm{Re} \\ \mathbf{5} & \mathbf{C} & \mathbf{5} & \mathbf{6} & \mathbf{5} & \mathbf{C} & \mathbf{5} & \mathbf{6} & 5 & \mathrm{Do} & 5 & \mathrm{Do} & 5 & \mathrm{Do} & 5 \text { Do }\end{array}$

3) Si está comprendido en un intervalo de séptima, por ejemplo:

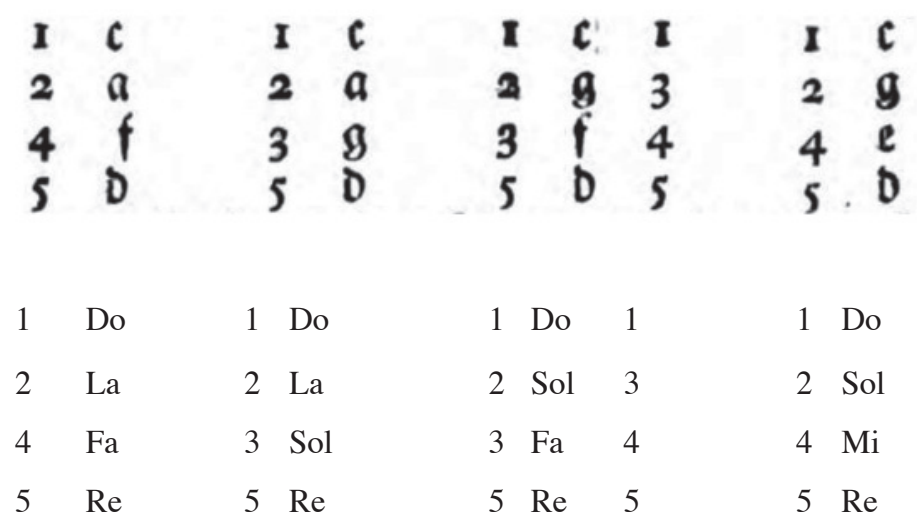

4) Si está comprendido en un intervalo de octava, por ejemplo:

$\begin{array}{llllllllllllllll}\mathbf{I} & \mathbf{C} & \mathbf{I} & \mathbf{C} & \mathbf{I} & \mathbf{C} & \mathbf{I} & \mathbf{C} & 1 & \text { Do } & 1 & \text { Do } & 1 & \text { Do } & 1 & \text { Do } \\ \mathbf{2} & \mathfrak{g} & \mathbf{2} & \mathfrak{a} & \mathbf{2} & \mathfrak{a} & \mathbf{2} & \mathfrak{g} & 2 & \text { Sol } & 2 & \mathrm{La} & 2 & \text { La } & 2 & \text { Sol } \\ \mathbf{4} & \mathbf{C} & \mathbf{4} & \mathbf{f} & \mathbf{4} & \mathbf{e} & \mathbf{3} & \mathbf{f} & 4 & \mathrm{Mi} & 4 & \mathrm{Fa} & 4 & \mathrm{Mi} & 3 & \mathrm{Fa} \\ \mathbf{5} & \mathfrak{C} & \mathbf{5} & \mathfrak{C} & \mathbf{5} & \mathbf{C} & \mathbf{5} & \mathbf{C} & 5 & \mathrm{Do} & 5 & \mathrm{Do} & 5 & \text { Do } & 5 & \text { Do }\end{array}$


Nota: Cuando haya un sostenido o un bemol delante de la nota inferior de un acorde en la mano derecha o la nota superior de un acorde en la mano izquierda, por comodidad, evítese la digitación con el pulgar y tómese otra.

En estos casos, el acorde que esté comprendido en un intervalo de séptima también puede tomarse con los dedos segundo y quinto.

Pero cuando tanto la nota superior como la inferior tienen delante una alteración, sírvase de cualquiera de los tipos de digitación señalados arriba, de acuerdo con las circunstancias.

Si las notas intermedias de un acorde estuvieran también alteradas, entonces esto no modificaría nada en la digitación.

\section{$\S .31$.}

Por lo que se refiere a los pasajes en los que una mano tiene que ascender o descender con notas sueltas, vamos a plantear los cambios de digitación más fáciles y cómodos en el orden de todas las tonalidades mayores y menores. 
Primer párrafo.

Sobre las tonalidades mayores, concretamente en la mano derecha $(\alpha)$.

Aquí, tanto al subir como al bajar, uno se sirve exactamente de los mismos dedos.

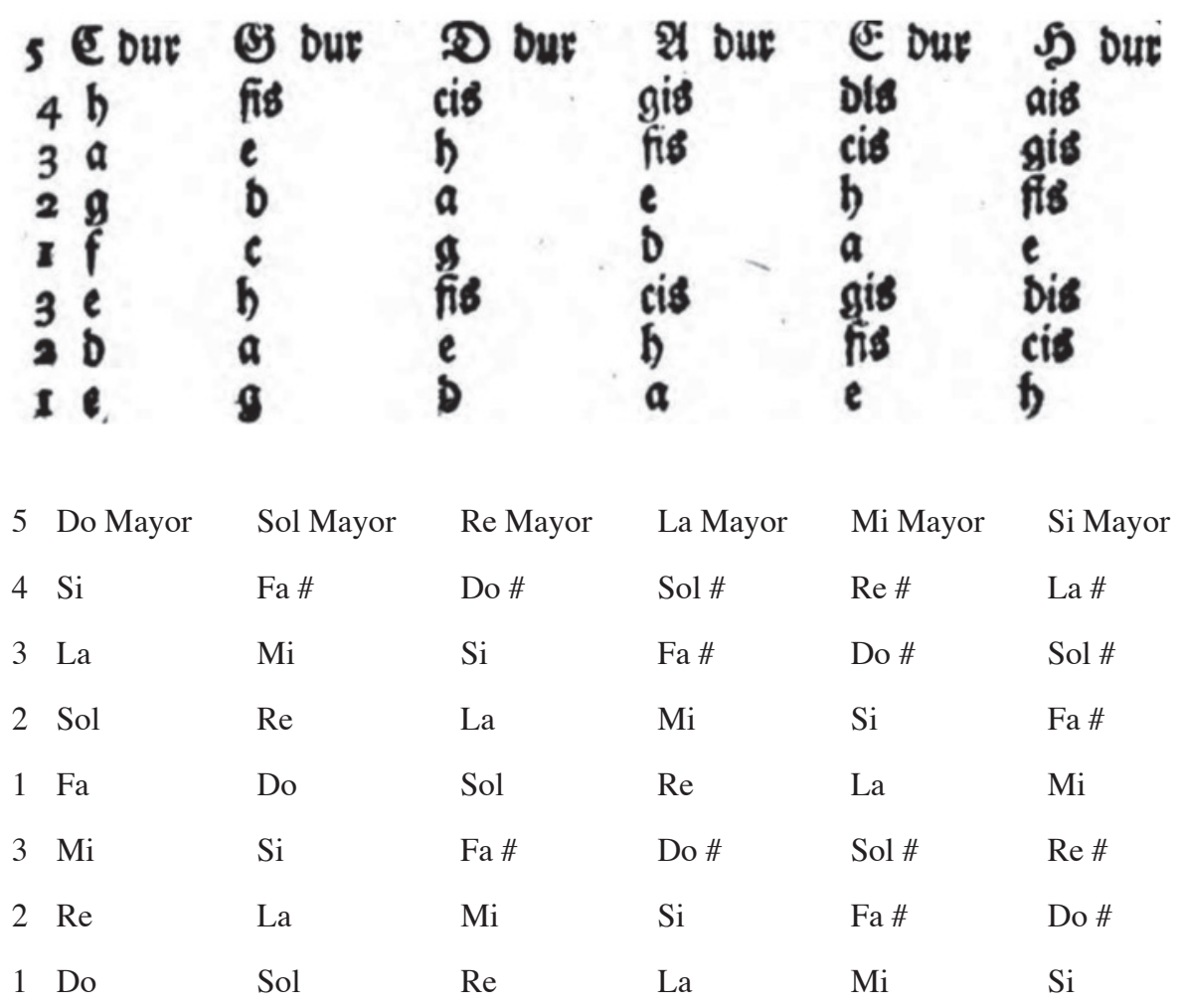

Las seis escalas anteriores se tocan todas con los mismos dedos, como se muestra para Do Mayor. Las siguientes difieren algo en su digitación. 


\begin{tabular}{|c|c|c|c|c|c|}
\hline $\begin{array}{l}4 \text { Four } \\
3 \mathrm{e}\end{array}$ & $\begin{array}{l}4 \mathfrak{B} \text { but } \\
3 \mathfrak{a}\end{array}$ & $\begin{array}{l}3 \text { ES but } \\
2 \mathrm{D}\end{array}$ & $\begin{array}{l}328 \text { bur } \\
2 \mathrm{~g}\end{array}$ & $\begin{array}{l}2 \text { Des bur } \\
1 \mathrm{c}\end{array}$ & ${ }_{\text {If }}^{2 \text { Seg Dur }}$ \\
\hline 20 & $2 \mathrm{~g}$ & I C & If & $4 b$ & 3 es \\
\hline I c & if & 46 & 3 es & 3 as & 2 Des \\
\hline $4 b$ & 3 es & 3 ด8 & 2 Des & 2 ged & I ces \\
\hline a & 20 & $2 \mathrm{~g}$ & I c & & $4 b$ \\
\hline$g$ & I c & $I \tilde{f}$ & 36 & $3 \mathrm{cb}$ & 3 as \\
\hline & 26 & $2 \mathrm{CB}$ & $2 a b$ & 2 DCb & $2 \mathrm{geb}$ \\
\hline
\end{tabular}

\begin{tabular}{|c|c|c|c|c|c|c|c|c|}
\hline 4 Fa Mayor & 4 Si b Mayor & 3 & Mi b Mayor & 3 & La b Mayor & 2 Re b Mayor & 2 Sol b & Mayor \\
\hline $3 \mathrm{Mi}$ & $3 \mathrm{La}$ & 2 & $\mathrm{Re}$ & 2 & Sol & 1 Do & $1 \mathrm{Fa}$ & \\
\hline $2 \mathrm{Re}$ & 2 Sol & 1 & Do & 1 & $\mathrm{Fa}$ & $4 \mathrm{Sib}$ & 3 Mi b & \\
\hline 1 Do & $1 \mathrm{Fa}$ & 4 & Si b & 3 & Mi b & $3 \mathrm{Lab}$ & $2 \operatorname{Re} b$ & o bien \\
\hline $4 \mathrm{Sib}$ & 3 Mi b & 3 & $\mathrm{La} b$ & 2 & $\operatorname{Re} b$ & $2 \mathrm{Sol} \mathrm{b}$ & 1 Do b & \\
\hline $3 \mathrm{La}$ & $2 \operatorname{Re}$ & 2 & Sol & 1 & Do & $1 \mathrm{Fa}$ & $4 \mathrm{Sib}$ & \\
\hline 2 Sol & 1 Do & 1 & $\mathrm{Fa}$ & 3 & Si b & $3 \mathrm{Mib}$ & $3 \mathrm{Lab}$ & \\
\hline $\mathrm{Fa}$ & $2 \mathrm{Sib}$ & 2 & Mi b & 2 & $\mathrm{Lab}$ & $2 \operatorname{Re} b$ & 2 Sol b & \\
\hline
\end{tabular}

(B) Para la mano izquierda.

Aquí de nuevo, tanto al subir como al bajar, uno se sirve exactamente de los mismos dedos.

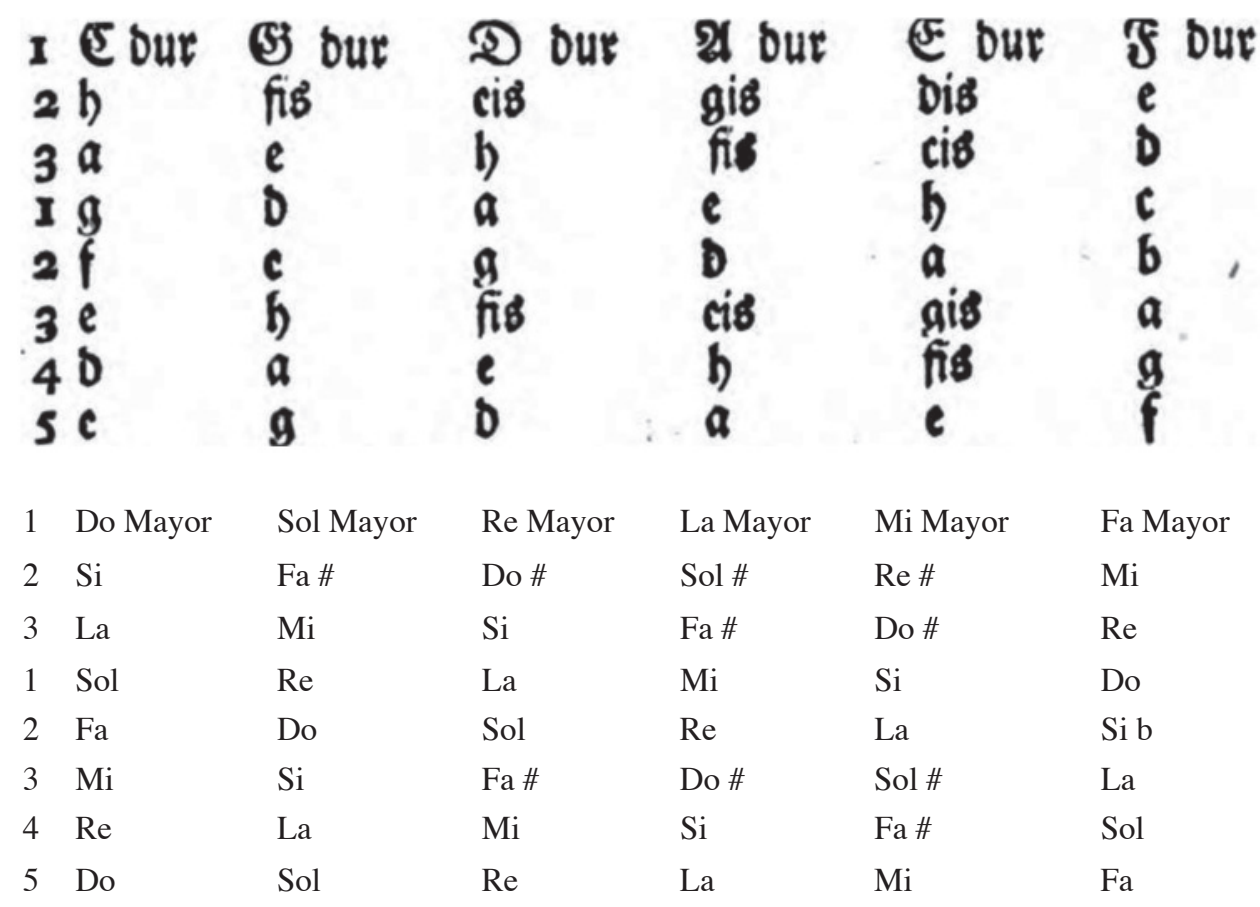


Las seis escalas anteriores se tocan todas con los mismos dedos, como se muestra para Do Mayor. Las siguientes difieren algo en su digitación ${ }^{4}$.

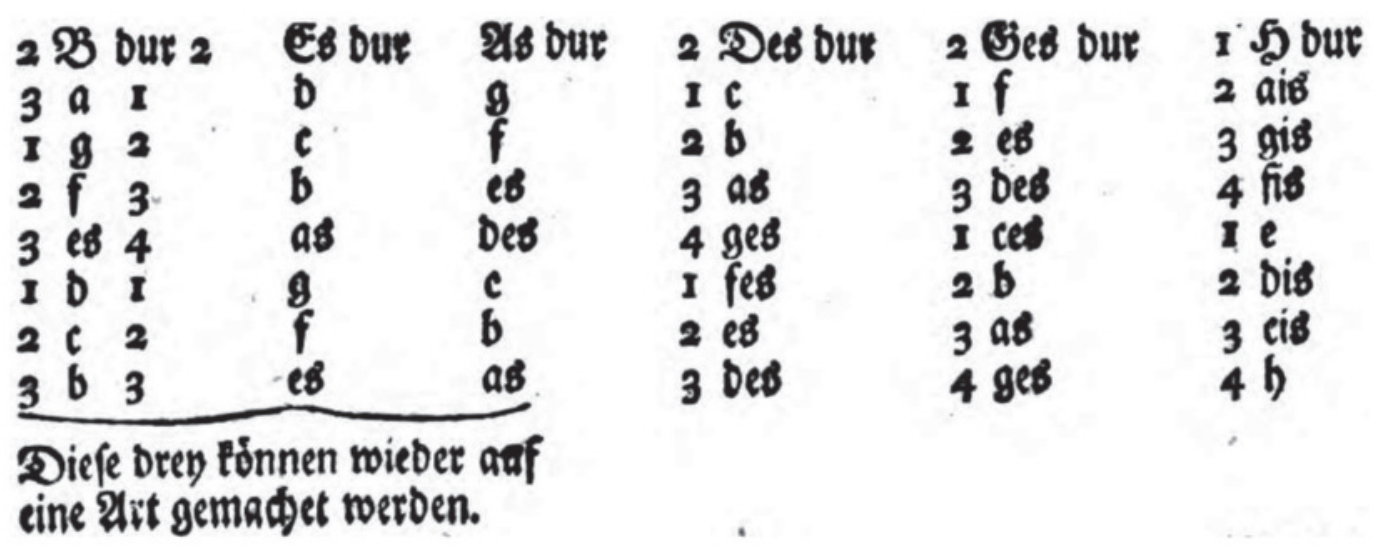

\begin{tabular}{|c|c|c|c|c|c|c|}
\hline 2 Si b Mayor & 2 & Mi b Mayor & La b Mayor & 2 Re b Mayor & 2 Sol b Mayor & 1 Si Mayor \\
\hline $3 \mathrm{La}$ & 1 & $\operatorname{Re}$ & Sol & 1 Do & $1 \mathrm{Fa}$ & $2 \mathrm{La \#}$ \\
\hline 1 Sol & 2 & Do & $\mathrm{Fa}$ & $2 \mathrm{Sib}$ & $2 \mathrm{Mib}$ & $3 \mathrm{Sol} \#$ \\
\hline $2 \mathrm{Fa}$ & 3 & Sib & Mi b & $3 \mathrm{Lab}$ & $3 \operatorname{Re} b$ & $4 \mathrm{Fa} \#$ \\
\hline 3 Mi b & 4 & $\mathrm{La} b$ & $\operatorname{Re} b$ & 4 Sol b & 1 Do b & $1 \mathrm{Mi}$ \\
\hline $1 \mathrm{Re}$ & 1 & Sol & Do & $1 \mathrm{Fa}$ & $2 \mathrm{Sib}$ & $2 \operatorname{Re} \#$ \\
\hline 2 Do & 2 & $\mathrm{Fa}$ & $\mathrm{Si} \mathrm{b}$ & 2 Mib & $3 \mathrm{Lab}$ & 3 Do \# \\
\hline $3 \mathrm{Si} \mathrm{b}$ & 3 & Mi b & $\mathrm{Lab}$ & $3 \operatorname{Re} b$ & 4 Sol b & $4 \mathrm{Si}$ \\
\hline
\end{tabular}

Estas tres [primeras] también pueden hacerse de una misma manera.

4 En la escala de Re bemol Mayor de la siguiente tabla, el Fa figura como Fa bemol en el original alemán (Fes). Sin duda se trata de una errata que he corregido en la traducción española. 


\section{Segundo párrafo}

\section{de las tonalidades menores, concretamente en la mano derecha $(\alpha)$.}

Aquí también se asciende y se desciende con los mismos dedos, a excepción de Do sostenido menor y Fa sostenido menor, y de que, si se contemplan los intervalos, al ascender hay una sexta y séptima mayores, pero al descender son menores ${ }^{5}$.

\begin{tabular}{|c|c|c|c|c|c|}
\hline $\begin{array}{ll}5 & \mathfrak{A} \text { moll } \\
4 & g i b(g) \\
3 & \text { fis (f) } \\
2 & e \\
1 & b \\
3 & c \\
2 & b \\
1 & a\end{array}$ & $\begin{array}{l}\text { D moll } \\
\text { cis (c)) } \\
b(b) \\
a \\
g \\
f \\
e \\
b\end{array}$ & $\begin{array}{l}\text { S moll } \\
\text { fis (f) } \\
e(c b) \\
b \\
c \\
b \\
a \\
b\end{array}$ & $\begin{array}{l}5 \text { moll } \\
b \text { (b) } \\
a \text { (ab) } \\
g \\
f \\
e b \\
b \\
c\end{array}$ & $\begin{array}{l}\text { (E) moll } \\
\text { bis (D) } \\
\text { cis (c) } \\
\text { b } \\
\text { a } \\
9 \\
\text { fis } \\
\text { e }\end{array}$ & $\begin{array}{l}\text { Ş moll } \\
\text { ais (a) } \\
\text { gis (g) } \\
\text { fis } \\
\text { e } \\
\text { b } \\
\text { cis } \\
\text { b }\end{array}$ \\
\hline
\end{tabular}

\begin{tabular}{|c|c|c|c|c|c|}
\hline 5 La menor & Re menor & Sol menor & Do menor & Mi menor & Si menor \\
\hline $4 \mathrm{Sol} \#(\mathrm{Sol})$ & Do \# (Do) & $\mathrm{Fa} \#(\mathrm{Fa})$ & $\mathrm{Si}(\mathrm{Si} \mathrm{b})$ & $\operatorname{Re} \#(\operatorname{Re})$ & $\mathrm{La} \#(\mathrm{La})$ \\
\hline $3 \mathrm{Fa} \#(\mathrm{Fa})$ & $\mathrm{Si}(\mathrm{Si} \mathrm{b})$ & Mi (Mi b) & $\mathrm{La}(\mathrm{La} b)$ & Do \# (Do) & Sol \# (Sol) \\
\hline $\mathrm{Mi}$ & $\mathrm{La}$ & $\mathrm{Re}$ & Sol & $\mathrm{Si}$ & $\mathrm{Fa} \#$ \\
\hline $1 \mathrm{Re}$ & Sol & Do & $\mathrm{Fa}$ & $\mathrm{La}$ & $\mathrm{Mi}$ \\
\hline 3 Do & $\mathrm{Fa}$ & Sib & Mi b & Sol & $\operatorname{Re}$ \\
\hline $2 \mathrm{Si}$ & $\mathrm{Mi}$ & $\mathrm{La}$ & $\operatorname{Re}$ & $\mathrm{Fa} \#$ & Do \# \\
\hline $1 \mathrm{La}$ & $\mathrm{Re}$ & Sol & Do & $\mathrm{Mi}$ & $\mathrm{Si}$ \\
\hline
\end{tabular}

Las seis escalas anteriores se tocan todas con los mismos dedos, como se muestra para La menor. Las siguientes cuatro difieren algo en su digitación.

5 Se refiere a la escala menor melódica. 


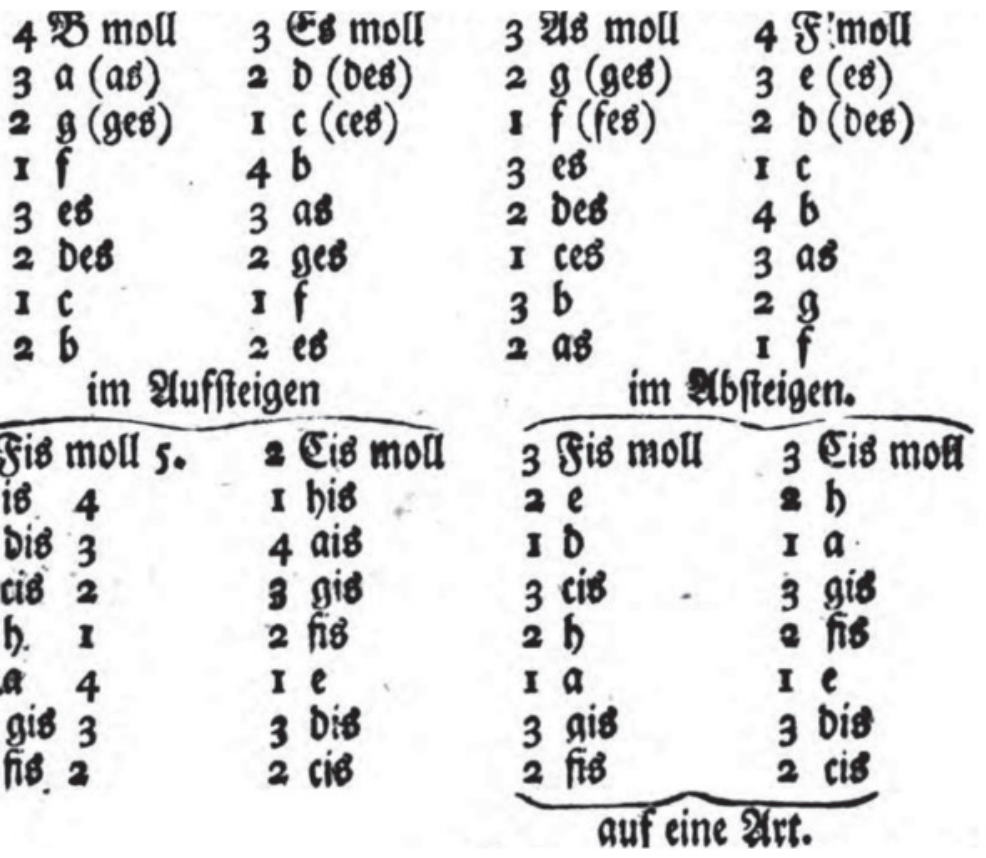

$\begin{array}{llllllll}4 & \text { Si b menor } & 3 & \text { Mi b menor } & 3 & \text { La b menor } & 4 & \text { Fa menor } \\ 3 & \text { La (La b) } & 2 & \text { Re (Re b) } & 2 & \text { Sol (Sol b) } & 3 & \text { Mi (Mi b) } \\ 2 & \text { Sol (Sol b) } & 1 & \text { Do (Do b) } & 1 & \text { Fa }(\text { Fa b }) & 2 & \text { Re }(\operatorname{Re~b)~} \\ 1 & \text { Fa } & 4 & \text { Si b } & 3 & \text { Mi b } & 1 & \text { Do } \\ 3 & \text { Mi b } & 3 & \text { La b } & 2 & \text { Re b } & 4 & \text { Si b } \\ 2 & \text { Re b } & 2 & \text { Sol b } & 1 & \text { Do b } & 3 & \text { La b } \\ 1 & \text { Do } & 1 & \text { Fa } & 3 & \text { Si b } & 2 & \text { Sol } \\ 2 & \text { Si b } & 2 & \text { Mi b } & 2 & \text { La b } & 1 & \text { Fa }\end{array}$

$\mathrm{Al}$ ascender:

$\begin{array}{lllll}2 & \mathrm{Fa} \# \text { menor } & 5 & 2 & \text { Do \# menor } \\ 1 \mathrm{Mi} \# & 4 & 1 & \mathrm{Si} \# \\ 4 & \mathrm{Re} \# & 3 & 4 & \mathrm{La} \# \\ 3 & \mathrm{Do} \# & 2 & 3 & \mathrm{Sol} \# \\ 2 & \mathrm{Si} & 1 & 2 & \mathrm{Fa} \# \\ 1 \mathrm{La} & 4 & 1 & \mathrm{Mi} \\ 3 & \mathrm{Sol} \# & 3 & 3 & \mathrm{Re} \# \\ 2 & \mathrm{Fa} \mathrm{\#} & 2 & 2 & \mathrm{Do} \#\end{array}$

Al descender:

$\begin{array}{llll}3 & \mathrm{Fa} \# \text { menor } & 3 & \mathrm{Do} \# \text { menor } \\ 2 & \mathrm{Mi} & 2 & \mathrm{Si} \\ 1 & \mathrm{Re} & 1 & \mathrm{La} \\ 3 & \mathrm{Do} \# & 3 & \mathrm{Sol} \# \\ 2 & \mathrm{Si} & 2 & \mathrm{Fa} \mathrm{\#} \\ 1 & \mathrm{La} & 1 & \mathrm{Mi} \\ 3 & \mathrm{Sol} \mathrm{\#} & 3 & \mathrm{Re} \# \\ 2 & \mathrm{Fa} & 2 & \mathrm{Do} \#\end{array}$

De una misma manera. 


\section{(B) Para la mano izquierda.}

Aquí de nuevo, tanto al subir como al bajar, uno se sirve exactamente de las mismas posiciones.
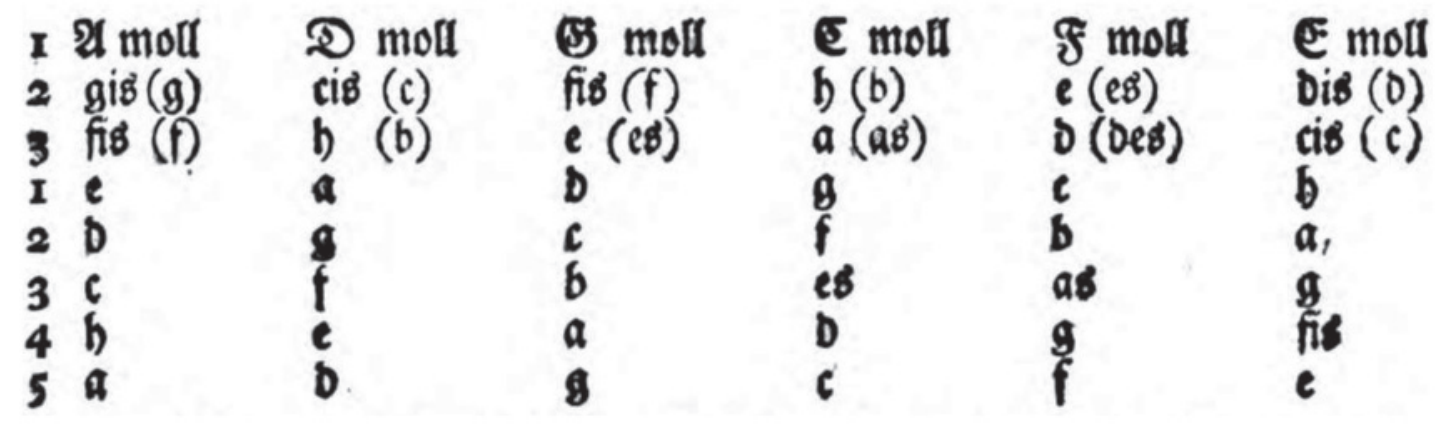

$\begin{array}{ll}1 & \text { La menor } \\ 2 & \mathrm{Sol} \mathrm{\#} \mathrm{(Sol)} \\ 3 & \mathrm{Fa} \mathrm{\#} \mathrm{(Fa)} \\ 1 & \mathrm{Mi} \\ 2 & \mathrm{Re} \\ 3 & \mathrm{Do} \\ 4 & \mathrm{Si} \\ 5 & \mathrm{La}\end{array}$

Re menor
Do \# (Do)
Si (Si b)
La
Sol
$\mathrm{Fa}$
$\mathrm{Mi}$
$\mathrm{Re}$

Sol menor
Fa \# (Fa)
Mi (Mi b)
Re
Do
Si b
La
Sol

Do menor
Si (Si b)
La (La b)
Sol
Fa
Mi b
Re
Do

Fa menor
Mi (Mi b)
$\operatorname{Re}(\operatorname{Re~b})$
Do
Si b
La b
Sol
Fa

Mi menor
$\mathrm{Re} \#(\mathrm{Re})$
$\mathrm{Do} \#(\mathrm{Do})$
$\mathrm{Si}$
$\mathrm{La}$
$\mathrm{Sol}$
$\mathrm{Fa} \#$
$\mathrm{Mi}$

Las seis escalas anteriores se tocan todas con los mismos dedos, como se muestra para La [menor]. Las siguientes seis difieren algo entre ellas. 
5 moll 2 fis moll

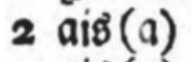

3 giв (g)

4 fis

Ie

20

3 cis

$4 h$
$I$ is (e)

$2 \operatorname{Dis}(0)$

3 cis

I b

$2 \mathfrak{a}$

3 gis

4 fis
2 Eisి moll

I bis (h)

2 aig (a)

3 gis

4 his

$1 \mathrm{e}$

2 bis

3 cis
2 2B moll 2 EB moll 2 mod

$3 \mathfrak{g}(\mathfrak{g e d})$

I f (fes)

$2 \mathrm{CB}$

3 Des

1 ces

26

3 as
$3 \mathrm{D}$ (Des) $3 \mathfrak{a}$ (as)

I $c$ (ces) $4 \mathrm{~g}$ (geB)

26

3 ab

4 ges

I f

$2 \mathrm{es}$
I f

$2 \mathrm{cs}$

3 bes

I C

26

\begin{tabular}{|c|c|c|c|c|c|c|c|c|c|c|c|}
\hline 1 & Si menor & 2 & $\mathrm{Fa} \mathrm{\#} \mathrm{menor}$ & 2 & Do \# menor & 2 & La b menor & 2 & Mi b menor & 2 & Si b menor \\
\hline 2 & $\mathrm{La} \#(\mathrm{La})$ & 1 & Mi \# (Mi) & 1 & $\mathrm{Si} \#(\mathrm{Si})$ & 3 & Sol (Sol b) & 3 & $\operatorname{Re}(\operatorname{Re} b)$ & 3 & $\mathrm{La}(\mathrm{La} b)$ \\
\hline & Sol \# (Sol) & 2 & $\operatorname{Re} \#(\operatorname{Re})$ & 2 & $\mathrm{La} \#(\mathrm{La})$ & 1 & $\mathrm{Fa}(\mathrm{Fa} \mathrm{b})$ & 1 & Do (Do b) & 4 & Sol (Sol b) \\
\hline 4 & $\mathrm{Fa} \#$ & 3 & Do \# & 3 & Sol \# & 2 & Mi b & 2 & $\mathrm{Sib}$ & 1 & $\mathrm{Fa}$ \\
\hline & $\mathrm{Mi}$ & 1 & $\mathrm{Si}$ & 4 & $\mathrm{Fa} \#$ & 3 & $\operatorname{Re} b$ & 3 & $\mathrm{La} b$ & 2 & $\mathrm{Mi} \mathrm{b}$ \\
\hline 0 & $\operatorname{Re}$ & 2 & $\mathrm{La}$ & 1 & $\mathrm{Mi}$ & 1 & Do b & 4 & Sol b & 3 & $\operatorname{Re} b$ \\
\hline 3 & Do \# & 3 & Sol \# & 2 & $\operatorname{Re} \#$ & 2 & Sib & 1 & $\mathrm{Fa}$ & 1 & Do \\
\hline 4 & $\mathrm{Si}$ & 4 & $\mathrm{Fa} \mathrm{\#}$ & 3 & Do \# & 3 & $\mathrm{Lab}$ & 2 & $\mathrm{Mi} \mathrm{b}$ & 2 & Si b \\
\hline
\end{tabular}




\section{§.32.}

Además de todas las maneras aquí presentadas para ascender o descender una octava [por grados conjuntos], observaremos algunas otras excepcionales, entre las cuales algunas pueden usarse adicionalmente si se dan las circunstancias, otras [maneras] sólo sirven para ejercitar los dedos, [y] otras son erróneas e incómodas, y por ello deben evitarse.

\section{Para la mano derecha.}

(I) $\mathrm{Al}$ descender:
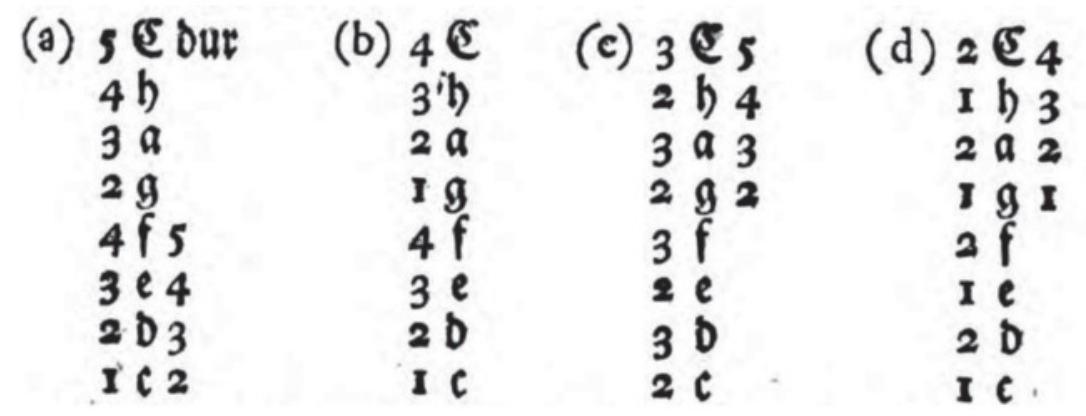

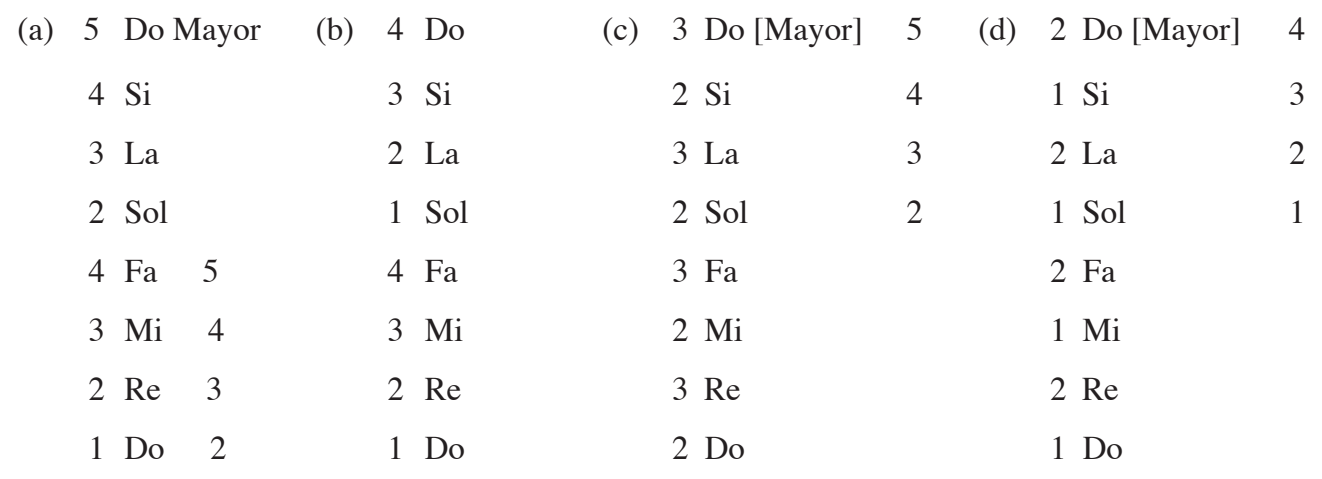

(a) Esta digitación puede hacerse al principio como mero ejercicio, en Sol Mayor, Re Mayor, La Mayor y Mi Mayor, así como en Mi menor, La menor, Re menor, y Do menor. Resulta demasiado cursi para su empleo [en el repertorio].

(b) Esta posición puede imitarse en Sol Mayor, Re Mayor, La Mayor y Mi Mayor, así como en Sol menor, Re menor, La menor, Mi menor y Do menor.

(c) Esta alternancia de los dedos tercero y segundo ${ }^{6}$ es buena; no obstante, debe hacerse sin forzar ni retorcer los dedos.

(d) También es buena esta posición en la que el segundo dedo sube sobre el pulgar.

6 En el original figura "tercero y cuarto" pero debe de tratarse, sin duda, de una errata, tal como puede comprobarse en el ejemplo de digitación (c) de la tabla anterior. 
(II) $\mathrm{Al}$ ascender:
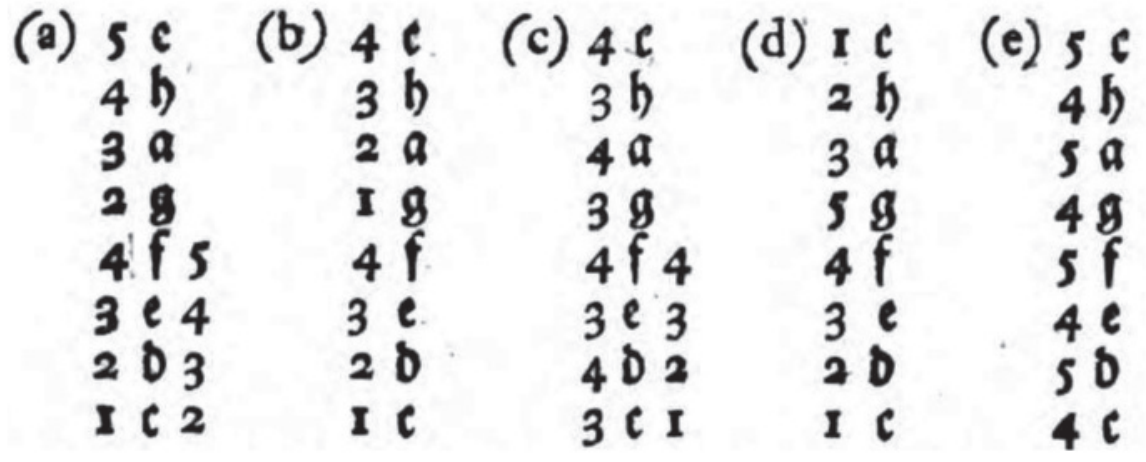

\begin{tabular}{|c|c|c|c|c|c|c|}
\hline 5 Do & (b) & 4 Do (c) & 4 Do & (d) & 1 Do & 5 Do \\
\hline $4 \mathrm{Si}$ & & $3 \mathrm{Si}$ & $3 \mathrm{Si}$ & & $2 \mathrm{Si}$ & $4 \mathrm{Si}$ \\
\hline $3 \mathrm{La}$ & & $2 \mathrm{La}$ & $4 \mathrm{La}$ & & $3 \mathrm{La}$ & $5 \mathrm{La}$ \\
\hline 2 Sol & & $1 \mathrm{Sol}$ & $3 \mathrm{Sol}$ & & $5 \mathrm{Sol}$ & 4 Sol \\
\hline $4 \mathrm{Fa}$ & 5 & $4 \mathrm{Fa}$ & $4 \mathrm{Fa}$ & 4 & $4 \mathrm{Fa}$ & $5 \mathrm{Fa}$ \\
\hline $3 \mathrm{Mi}$ & 4 & $3 \mathrm{Mi}$ & $3 \mathrm{Mi}$ & 3 & $3 \mathrm{Mi}$ & $4 \mathrm{Mi}$ \\
\hline $2 \mathrm{Re}$ & 3 & $2 \mathrm{Re}$ & $4 \mathrm{Re}$ & 2 & $2 \mathrm{Re}$ & $5 \mathrm{Re}$ \\
\hline 1 Do & 2 & 1 Do & 3 Do & 1 & 1 Do & 4 Do \\
\hline
\end{tabular}

(a) y (b). Véanse las notas (a) y (b) anteriores.

(c) Esta digitación es buena, pero debe hacerse sin forzar ni retorcer los dedos.

(d) y (e). Ambas posiciones son erróneas y despreciables. 
Para la mano izquierda.

(I) $\mathrm{Al}$ descender:

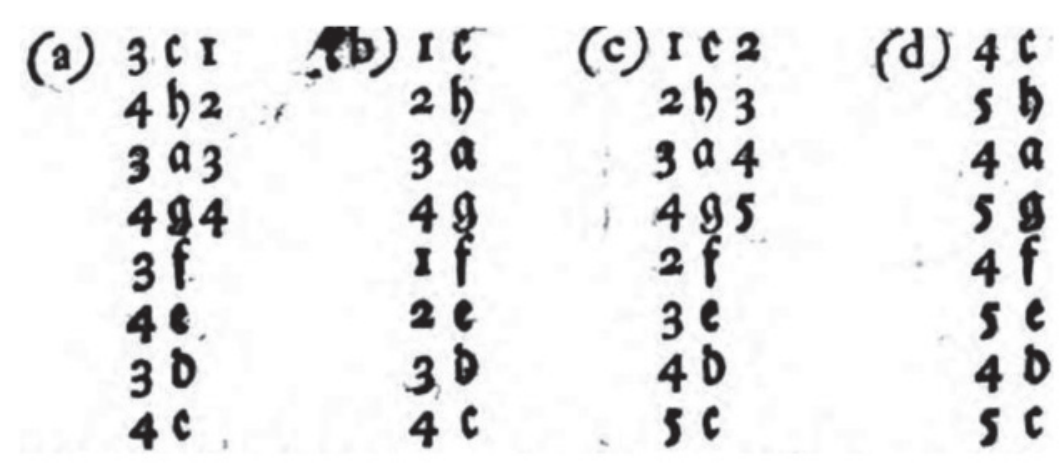

\begin{tabular}{|c|c|c|c|c|c|c|c|}
\hline (a) & Do & $1 \quad$ (b) & 1 Do & (c) & 1 Do & $2 \quad(d)$ & 4 Do \\
\hline 4 & $\mathrm{Si}$ & 2 & $2 \mathrm{Si}$ & & $2 \mathrm{Si}$ & 3 & $5 \mathrm{Si}$ \\
\hline 3 & $\mathrm{La}$ & 3 & $3 \mathrm{La}$ & & $3 \mathrm{La}$ & 4 & $4 \mathrm{La}$ \\
\hline 4 & Sol & 4 & 4 Sol & & 4 Sol & 5 & 5 Sol \\
\hline 3 & $\mathrm{Fa}$ & & $1 \mathrm{Fa}$ & & $2 \mathrm{Fa}$ & & $4 \mathrm{Fa}$ \\
\hline 4 & $\mathrm{Mi}$ & & $2 \mathrm{Mi}$ & & $3 \mathrm{Mi}$ & & $5 \mathrm{Mi}$ \\
\hline 3 & $\operatorname{Re}$ & & $3 \mathrm{Re}$ & & $4 \mathrm{Re}$ & & $4 \mathrm{Re}$ \\
\hline 4 & Do & & 4 Do & & 5 Do & & 5 Do \\
\hline
\end{tabular}

(a) Esta posición es buena, pero debe hacerse sin forzar ni retorcer los dedos.

(b) Ésta puede imitarse en Sol Mayor, Re Mayor, La Mayor y Mi Mayor, así como en Re menor, La menor, Mi menor y Do menor.

(c) Ésta no sirve para nada más que como ejercicio al principio.

(d) Ésta es despreciable y fea. 
(II) Al ascender:

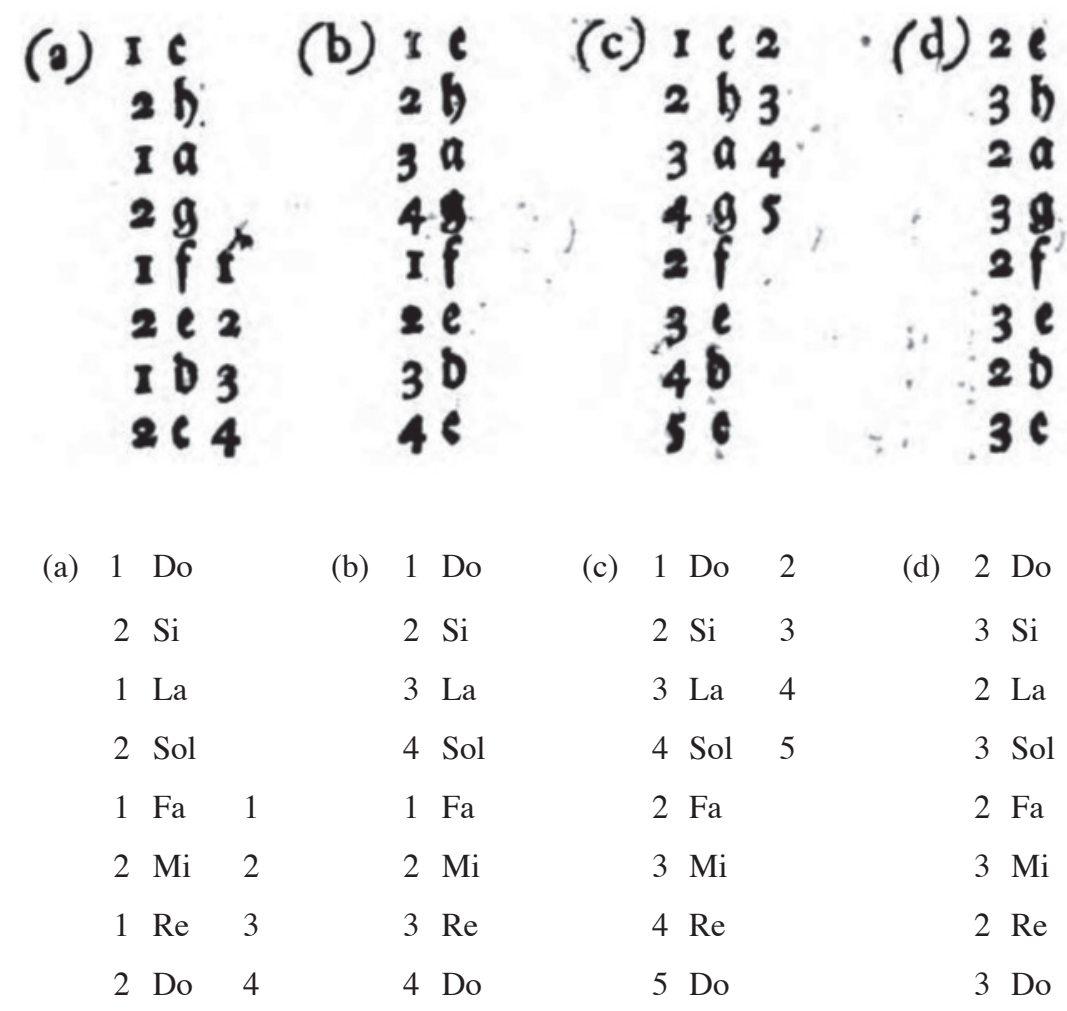

(a) Es buena.

(b) Puede imitarse en Sol Mayor, Re Mayor, La Mayor y Mi Mayor, así como en Re menor, La menor, Mi menor y Do menor.

(c) Sirve como mero ejercicio.

(d) Es incómoda y errónea. 


\section{$\S .33$.}

Una figura compuesta de notas repetidas, o redoble, se hace intercambiando dos dedos, concretamente con los dos primeros o con el segundo y tercero (véase No. 10, Tabla I). Por muy nuevo que resulte, el modo de tocar esta figura con los cinco dedos es una de las cosas más abominables.

\section{§.34.}

A continuación siguen todo tipo de anotaciones sobre los ejercicios y ejemplos que se encuentran en las planchas de cobre.

\section{Sobre la primera tabla.}

No. 1. Este ejemplo se puede transportar a otros tonos diferentes con la digitación que se encuentra aquí, como por ejemplo a Sol Mayor, Re Mayor, La Mayor y Mi Mayor.

No. 2. Tras el modelo de este ejemplo, pueden seguir todas las doce escalas mayores presentadas arriba, con ambas manos, en movimiento contrario.

No. 3. Aquí se muestra el modo de ejecutar una serie de apoyaturas intercambiando los dedos en la misma nota consecutivamente.

\section{Sobre la segunda tabla.}

No. 1. Tras el modelo de este ejemplo, pueden seguir despuéstodos los tonos. La digitación siempre es aquí la secuencia natural de los cinco dedos, uno tras otro. Ésta sirve para el mero ejercicio, pues para su uso habitual suele resultar demasiado forzada.

No. 2. En estos ejemplos, en los que se asciende y se desciende una séptima en movimiento contrario, debe tenerse en cuenta expresamente la digitación que figura, pues no hay ninguna más cómoda.

No. 3. Este ejemplo sólo compete a la mano izquierda.

\section{Sobre la tercera tabla.}

Nos. 1 al 6. En todos estos ejemplos se encuentran todo tipo de movimientos por grados conjuntos en segundas, terceras, cuartas, quintas, sextas y séptimas, [y aquéllos que] se tocan con ambas manos en octavas. Para ahorrar espacio, a partir del segundo compás del No. 2, se ha empezado a anotar estos ejemplos en un sistema. La clave de Fa que se encuentra aquí en la quinta línea, se tomará una octava más alta que habitualmente y se recordará que las cifras superiores constan para la mano derecha y las inferiores para la izquierda, como ya se ha dicho arriba. Esto vale también para los siguientes Nos. 7 y 10.

Núm. 7. Aquí se muestra el modo de conectar cómodamente unos trinos detrás de otros.

Núm. 9. En este caso y en otros parecidos, si se desea, se puede utilizar dos veces seguidas un mismo dedo.

Núm. 10. La digitación que hay aquí debe tenerse en cuenta en pos de la mayor conexión entre las notas que proceden por salto. 


\section{Sobre la cuarta tabla.}

Nos. 1 y 2. Estos dos ejemplos pueden transportarse, como ejercicio, a otras tonalidades, con algunas modificaciones en los dedos en los que resulte necesario.

Nos. 3, 4, 5 y 6 . Aquí hay todo tipo de intervalos por salto.

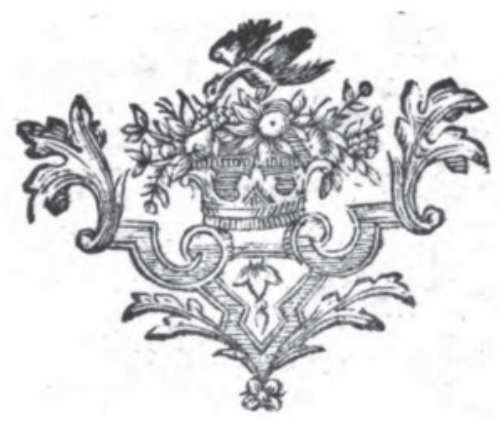




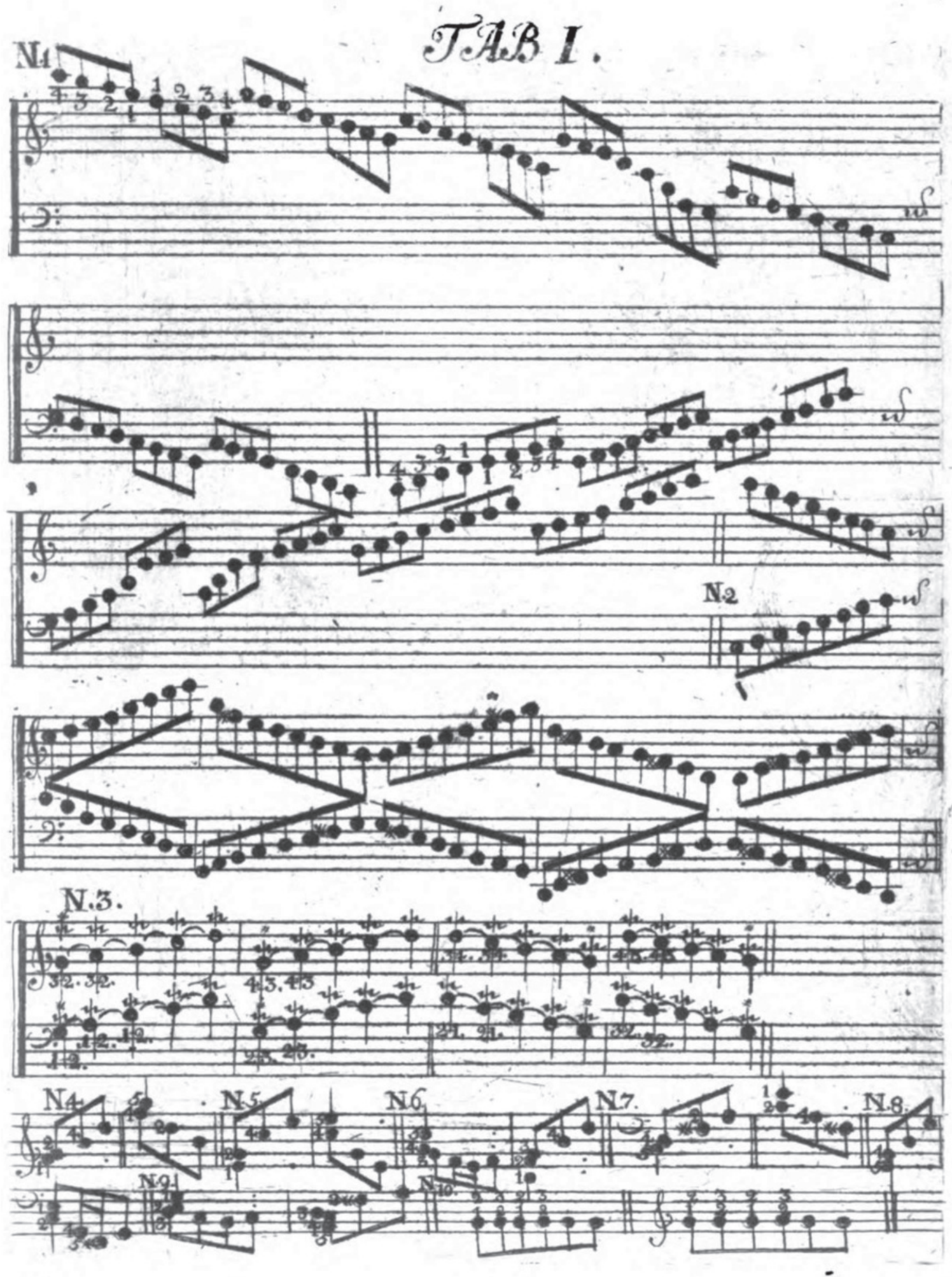




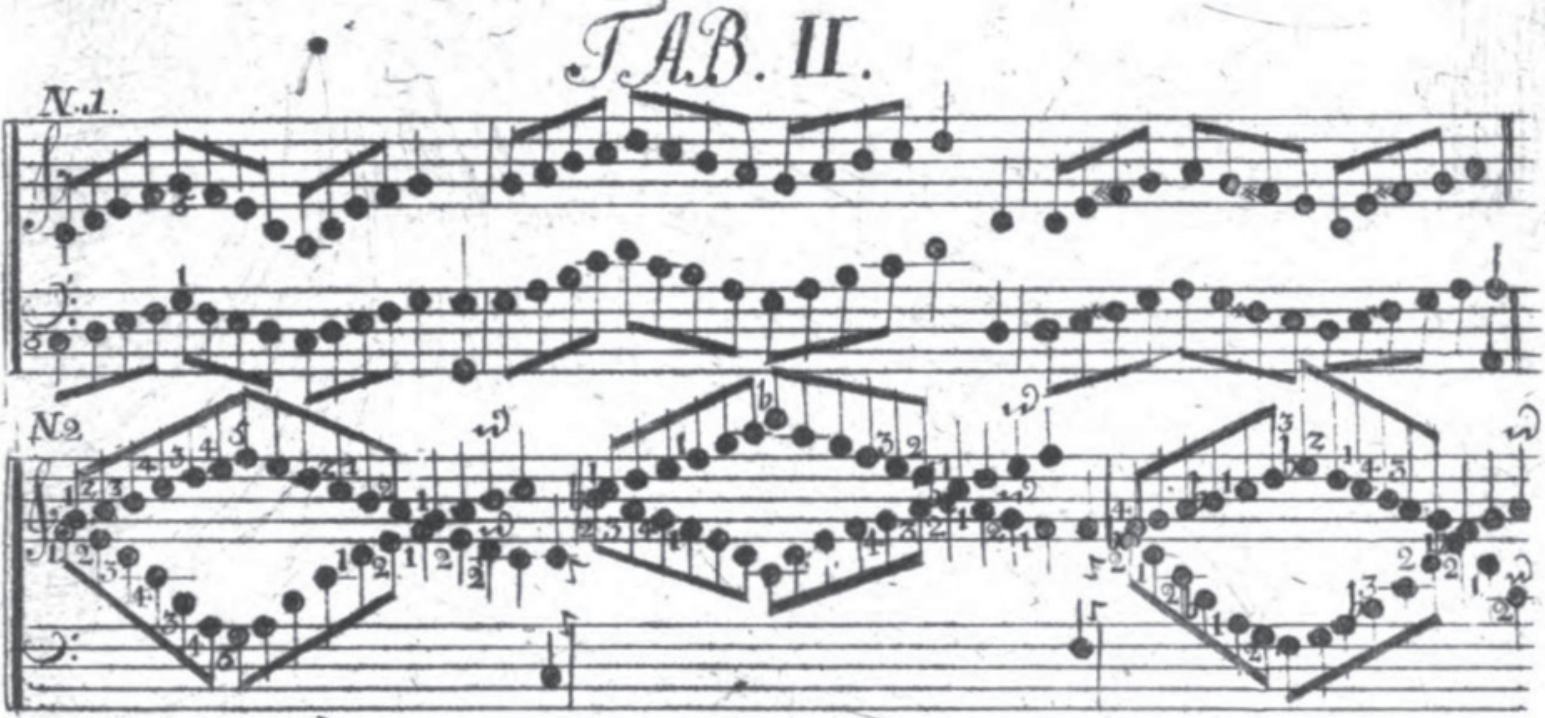

TAB. II.

$\int_{-0}^{\pi .1}$.

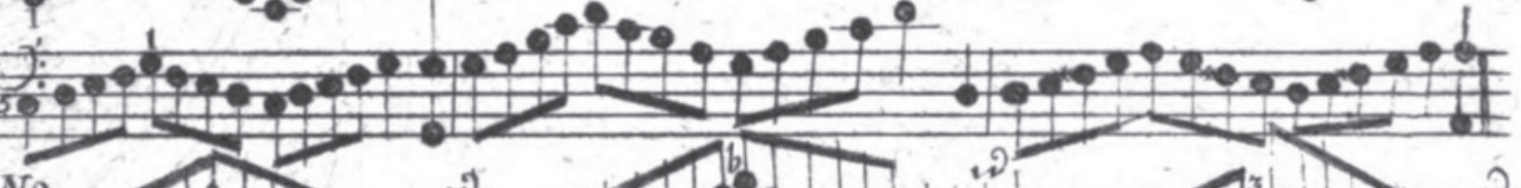

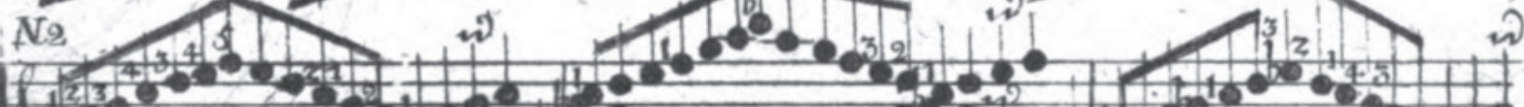

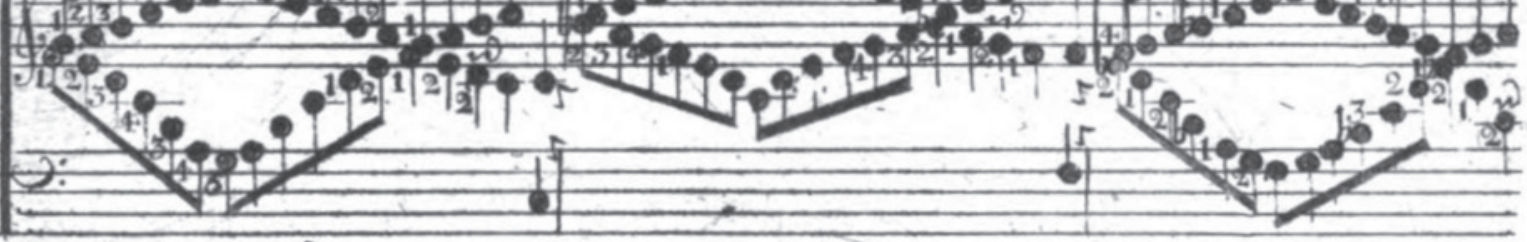

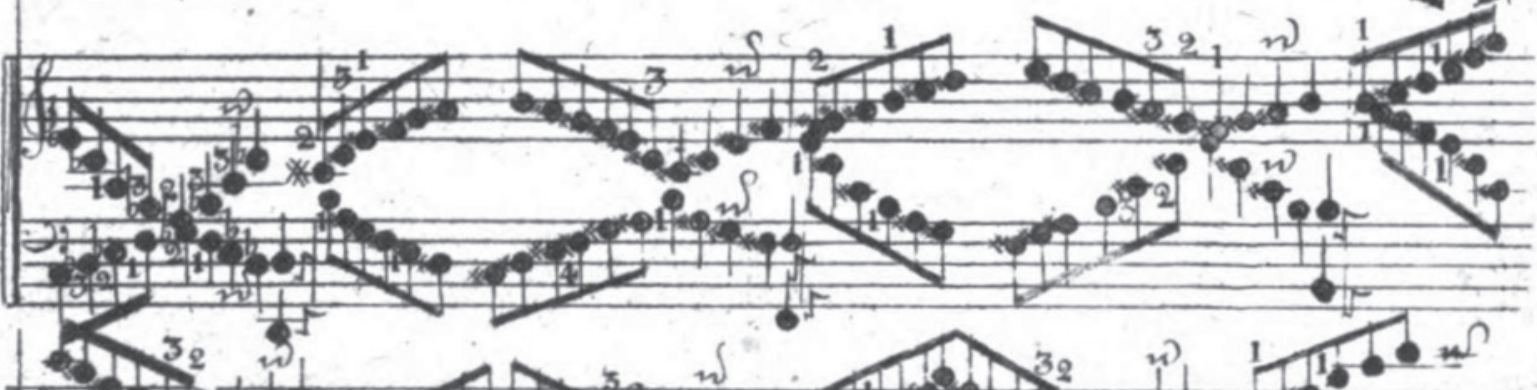

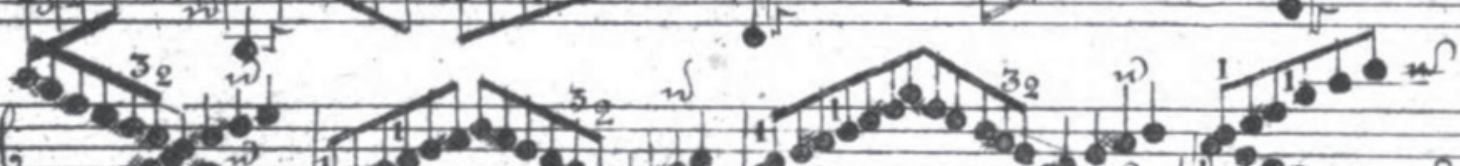

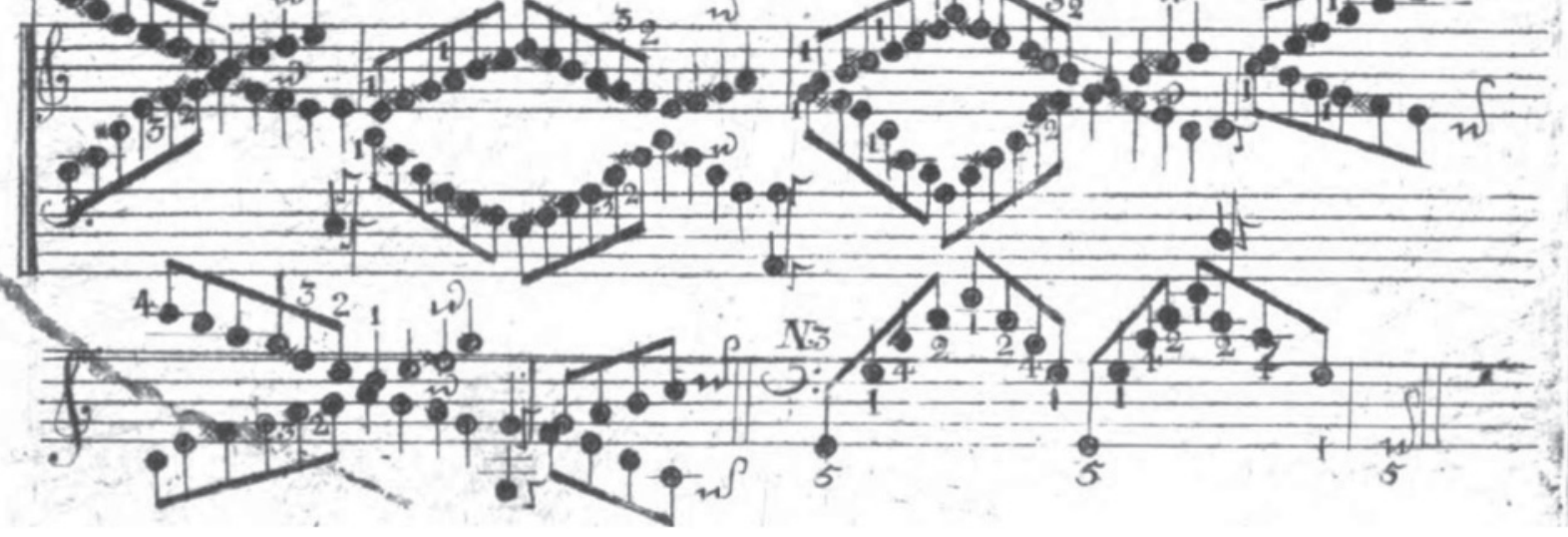


IV.1. ${ }_{43}$, J.AB. III. N.2.

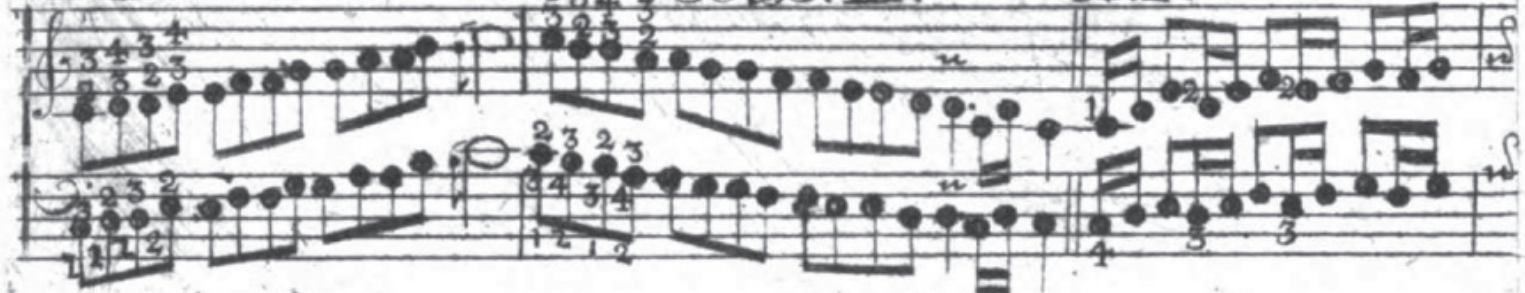

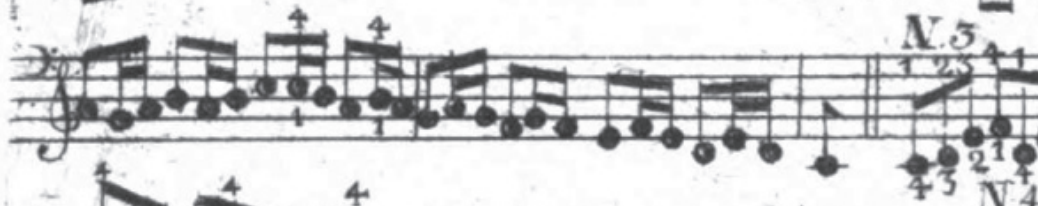

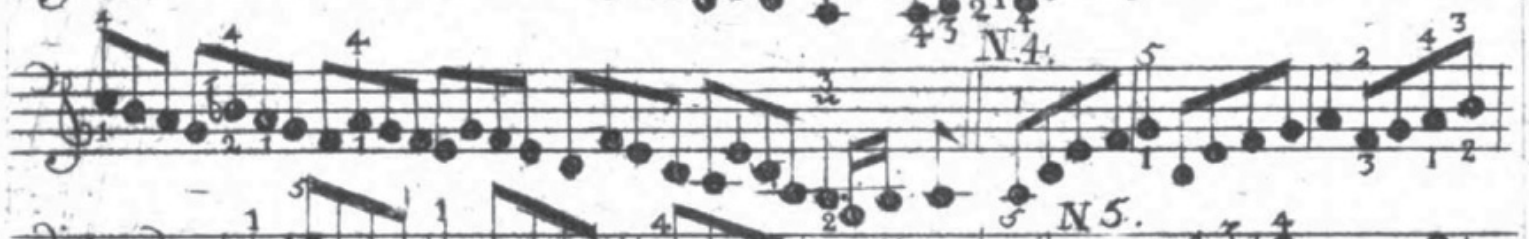

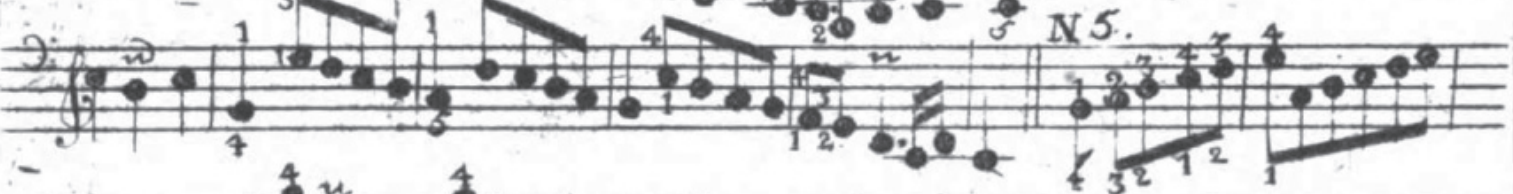

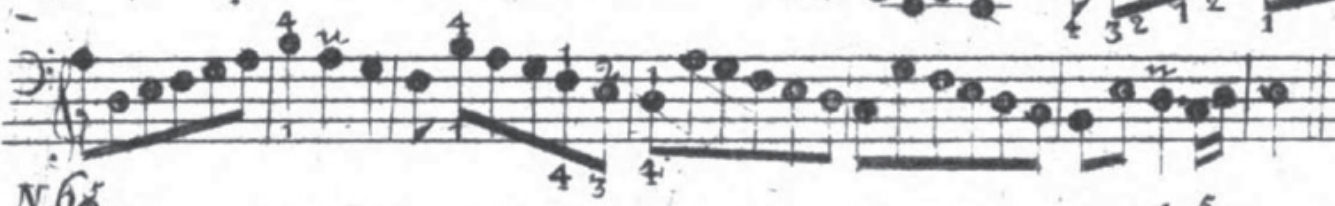

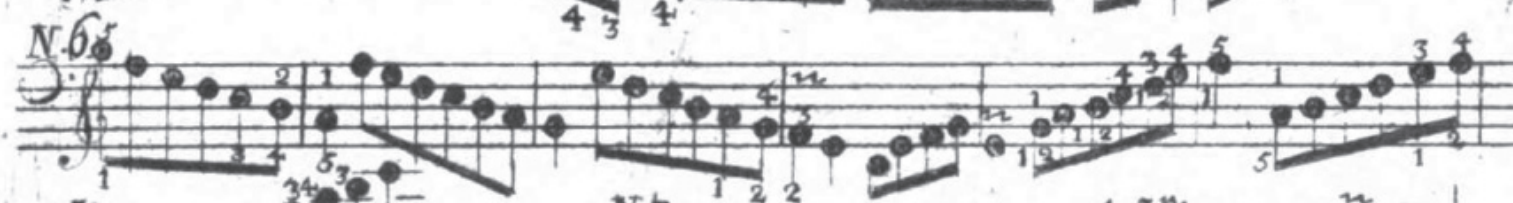

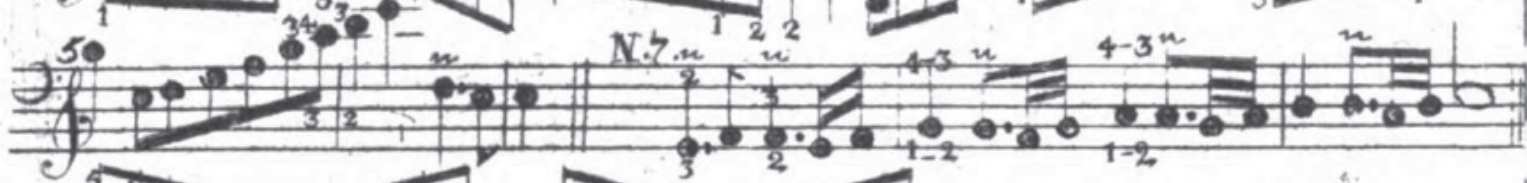

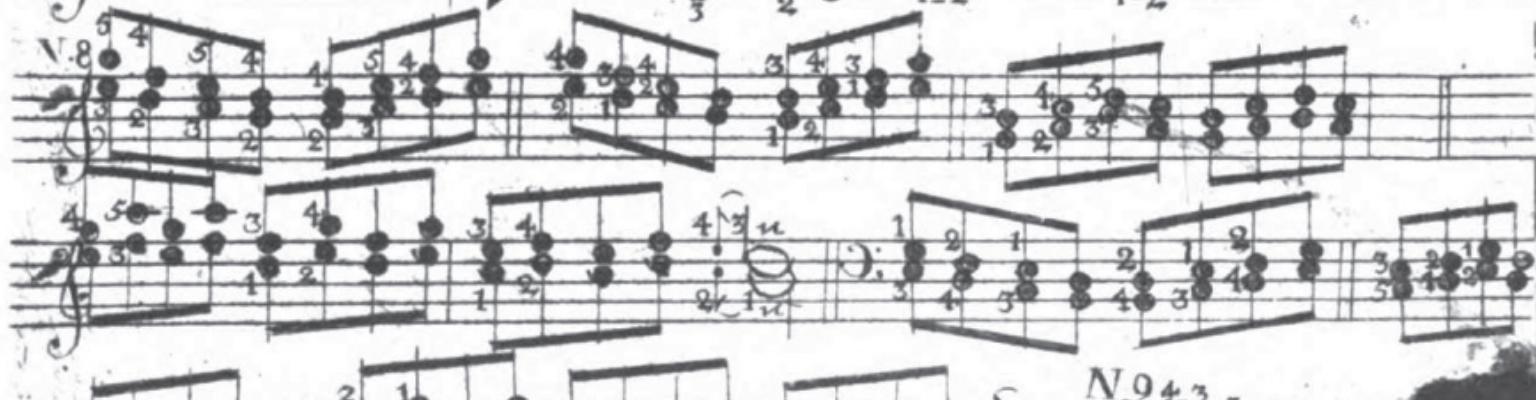

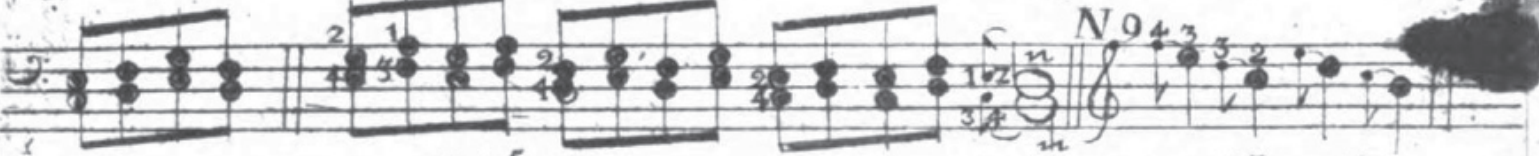

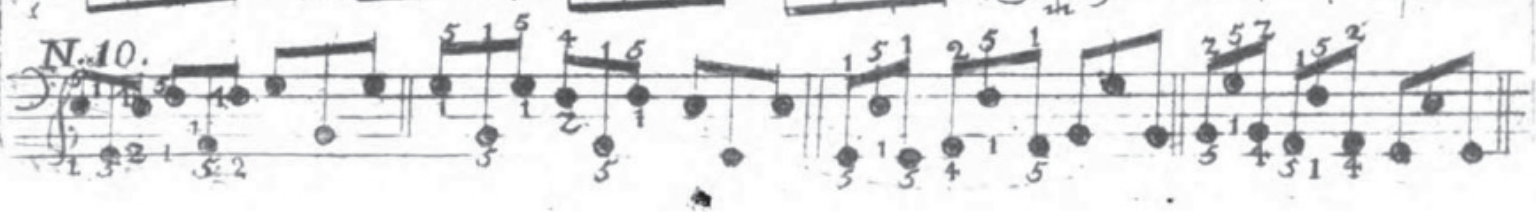




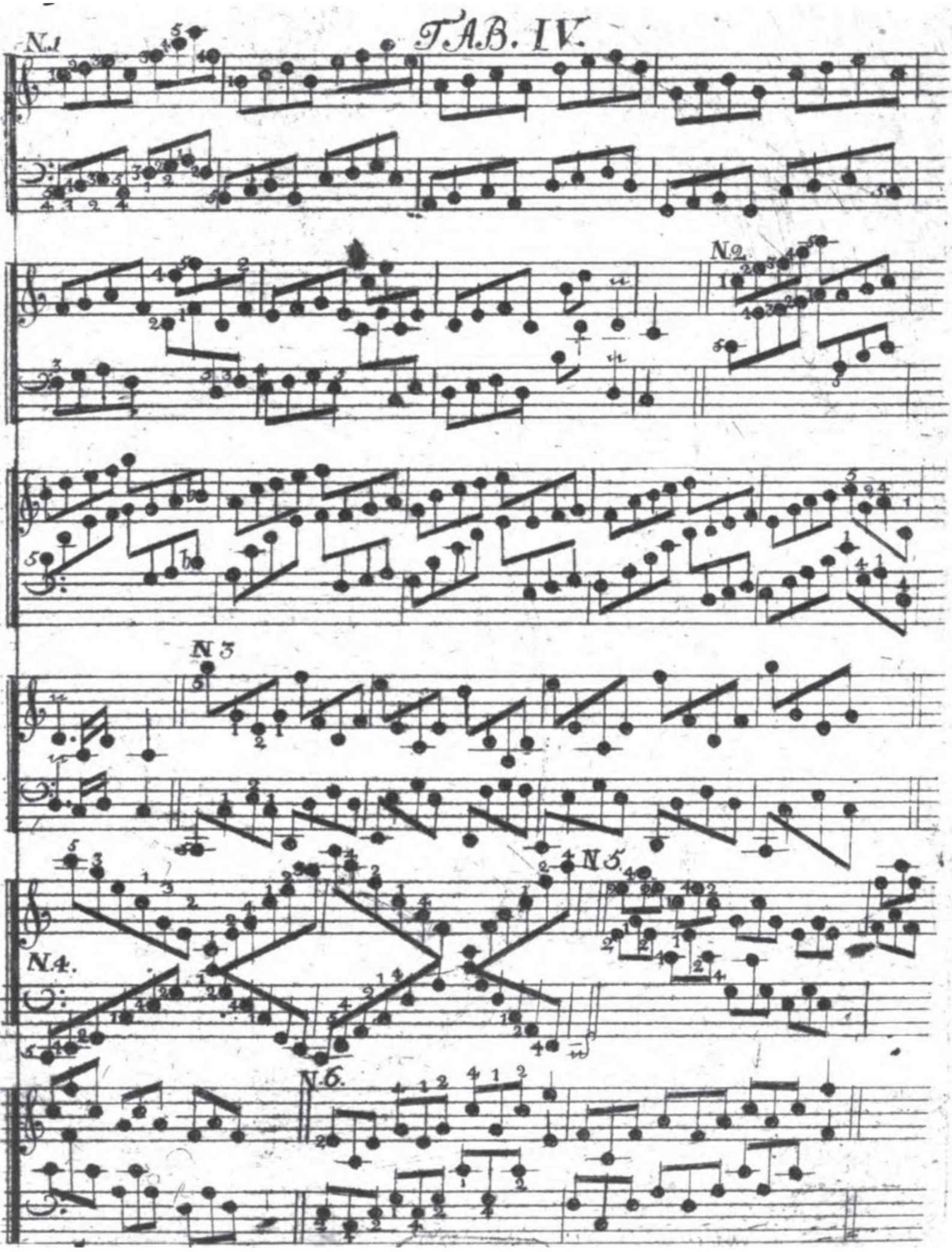


